\title{
A NEW STUDY OF THE LEUCOSCOPE AND ITS APPLICATION TO PYROMETRY:*
}

\author{
BY \\ IRWIN G. PRIEST. \\ CONTENTS.
}

I. INTRODUCTION.

I. History of the Leucoscope.

2. Design and Essential Principles of the Leucoscope.

3. Summary of Conclusions from Early Work.

4. Limitations of Early Work.

5. Purpose and Scope of the Present Paper.

II. Apparatus and Methods Used in the Present Investigation.

I. The Arons Chromoscope and its Use as a Leucoscope.

2. Pyrometric Calibration. Temperature Scale.

III. Empiric Results of Pyrometric Calibration.

IV. Discussion of the Empiric Results as to Pyrometric Accuracy.

I. Precision.

2. Personal Equation.

3. The Constancy of the Personal Equation.

4. Total Uncertainty of Temperature Reading from Calibration Curve.

5. Possible Practical Use of the Leucoscope as a Pyrometer.

V. The Laws of the Leucoscope.

I. The Relation Between the Leucoscope Reading and the Spectral Distribution of Light from the Source.

2. The Essential Condition that is Satisfied in Making the Leucoscope Setting.

VI. Experiments on. the Leucoscopic Determination of the Qunlity of Sunlight and its Diurnal Variation.

VII. General Summary and Conclusion.

Appendix I. The Computation of Spectral Transmission by Rotatory Dispersion.

Appendix II. Bibliographìy.

* Published by permission of the Director, Bureau of Standards. This paper is an amplification and extension of a paper under similar title by Priest and Foote, presented orally at the New York meeting of the Optical Society of America, February 27, 1920, but not printed. For lack of time, Dr. Foote has been obliged to abandon the original plan of completing this work as a joint investigation. The present author desires to express, however, his hearty appreciation of Dr. Foote's assistance and advice and also of the lively interest he has taken in the work. The author is also indebted to Dr. K. S. Gibson, Messrs. C. M. Blackburn, H. J. McNicholas and Mark Malamphy for assistance. Most of the figures have been prepared by Mr. Chester L. Snow and Miss Gertrude Clemens. 


\section{INTRODUCTION. $\dagger$}

I. History of the Leucoscope.

"Books are sepulchres of thought;

The dead laurels of the dead

Rustle for a moment only,

Like withered leaves in lonely

Churchyards at some passing tread."-Longfellow.

THIs paper deals with a new study of an old optical instrument, practically unknown to contemporary science-the leucoscope. The invention of this instrument is commonly attributed to Helmholtz ${ }^{1}$ (about I878-I882), but it appears that a very similar instrument under another name, "Farbenmesser," was really practically used by Rose in the diagnosis of color-blindness at an earlier date (I863): 2 The name, "leucoscope" (Greek: white + view ), was apparently coined by Kitao, ${ }^{3}$ a pupil of Helmholtz, in his doctor's thesis, Zur Farbenlehre, I878. From I873 to $I 888$ a number of papers dealing with this instrument were published by Helmholtz's pupils, Kitao, Koenig and Brodhun. ${ }^{*}$

The potentialities of the instrument as a means of investigation in two distinct fields, vision and the character of the emission of light sources (in modern terms, spectral distribution, color temperature) were clearly pointed out by these early investigators. Koenig, particularly, made a rather extensive series of leucoscopic observations ${ }^{5}$ on various light sources, including the

$\dagger$ Prospective readers of this paper should first familiarize themselves with a paper by Koenig, "Das Leucoscope . . .,"Ann. der Phy. und Chem., 17, pp. 990-1008, year I882. A complete bibliography is given in Appendix II to the present paper; but an acquaintance with this one paper by Koenig will be sufficient to give the reader an understanding of the subject, and prepare him to read the present paper intelligently.

${ }^{1} \mathrm{Cf}$. papers by Koenig and Brodhun (see Appendix II, this paper) and Webster's International Dictionary, I9Io ed.

${ }^{2}$ Rose's instrument could not, however, have been used by trichromatic observers as the leucoscope is, because he prescribes a fixed thickness of quartz of only $5 \mathrm{~mm}$. (Archiv für path. Anat. 28, p. 36), whereas from about two to four times this thickness is necessary to make use of the leucoscope principle. (See Section I-2 below.)

${ }^{3}$ There appears to be some doubt and controversy as to the relative contributions of Kitao, and his master, Helmholtz, in the original design and naming of the instrument. (Cf. last section of Kitao's second paper. For reference, see Appendix II.)

${ }^{4}$ See bibliography, Appendix II to this paper.

${ }^{5}$ Ann. der Phy. und Chem., I7, pp. I003-1008; year 1882. 
just then newly introduced carbon filament lamps ${ }^{6}$ of Swan and Edison; and tabulated the latter results as a function of current and candlepower. Notwithstanding these early promises of its utility in two important fields of scientific investigation, the instrument appears to have fallen into almost complete oblivion since the appearance of Brodhun's paper in $1888 .^{7} \quad$ So far as can be found, no later papers dealing .with it have been published. There is indeed occasional casual reference to it in works dealing with vision; ${ }^{8}$ but these merely serve to indicate that no practical use is made of the instrument, and indeed that the authors themselves have but slight acquaintance with it. So far as I can find, recent and contemporary authorities ${ }^{9}$ on pyrometry, spectral distribution and color temperature make absolutely no mention of this instrument; and it is apparently quite unknown to present-day pyrometry. It is not indexed and apparently not mentioned in many of the best known standard works of reference on physics, optics, chromatics and pyrometry. ${ }^{10}$ In declining to quote price on a leucoscope in reply to a recent request, the original makers ${ }^{11}$ state that there never was any demand for the instrument and that

s "The carbon filament lamp was developed about the year 1878 . . ."Solomon: "Electric Lamps," p. 95 ; London, Ig08.

"In I879, Swan exhibited a lamp with a filament of carbon in a vacuum bulb, and followed this by various improvements."-New Int. Enc. (I9I8 Ed.), Vol. 21, p. 7I5.

"The Edison incandescent lamp was first exhibited in I879 . . . ." New Int. Enc. (I9I8 Ed.), Vol. 7, p. 599.

On the 2oth of October, I880, Sir Joseph Wilson Swan gave at Newcastle the first public exhibition on a large scale of electric lighting by means of glow lamps-Enc. Brit. (IIth Ed., I9II), Vol. 26, p. I79, under "Swan, Sir Joseph Wilson."

"The author is indebted to his former associate, Mr. P. V. Wells, for having first directed his attention to the leucoscope. Mr. Wells happened to notice Koenig's paper in the Annalen der Physik while searching the literature on another subject.

${ }^{8}$ Norris and Oliver: "System of Diseases of the Eye," Vol. II ("Detection of Color Blindness," Wm. Thompson), p. 347. Tscherning: "Physiologic Optics," Eng. trans. by Weiland, p. 270; The Keystone Press, Philadelphia, I904.

${ }^{\circ}$ For example, G. K. Burgess, Block, Hyde, H. E. Ives, L. A. Jones, P. D. Foote. Cf. also Appendix II to this paper.

${ }^{10} \mathrm{Cf}$. Appendix II.

${ }^{11}$ Schmidt and Haensch, Cf. Zeit. fïr Instk., 3, p. 20, Jan., I883. 
they have not made one for about twenty years. The leucoscope has been buried in the uncut pages of scientific papers.

\section{Design and Essential Principles of the Leucoscope.}

The essential principle of the leucoscope design is this: Two juxtaposed images of a rectangular aperture produced by double refraction are viewed through a nicol prism and a variable thickness of crystalline quartz, the nicol being between the eye and the quartz, and the optic axis of the latter being coincident with the line of sight. ${ }^{12}$

To a normal observer, with "white" light illumination, the two images appear, in general, in complementary colors, of unequal brilliance. If another nicol be interposed between the doubly refracting part (calcite rhomb) and the light source, it may be set so as to equalize the brilliance of the two images, leaving them still complementary in color.

Experimental spectroscopic analysis, as well -as theoretical consideration based on the rotatory dispersion of the quartz, shows that the spectra of both images are banded ${ }^{13}$ and, in particular :

( I) The bands become narrower and more closely spaced as the thickness. of quartz is increased.

(2) The system of bands moves through the spectrum as the ocular nicol is rotated.

(3) The bright bands of one image coincide with the dark bands of the other, and conversely; that is, the wavelengths of the maximum and minimum intensity in the two images respectively coincide. The two images are physically complementary in the sense that the light absent from one is in the other.

Trichromatic observers find the following phenomena:

(I) For all thicknesses of quartz greater than about $9 \mathrm{~mm}$., there are found certain positions of the ocular nicol (one in each quadrant), for which both images are very pale (very nearly

${ }^{13}$ For diagrams of design, consult any one of the following papers : Koenig: Ann. der Phy. und Chem., 17, p. 990; Koenig: Zeit. für Instk., 3, p. 20; Brodhun: Ann. der Phy. und Chem., 34, p. 897.

${ }^{13} \mathrm{Cf}$. Appendix I and Figs. I 3 and 14 , this paper. 
white) and, accordingly, very nearly color matched. One may be a very pale blue; the other a very pale yellow; neither may be recognized as more reddish than the other. This is the criterion for the leucoscope setting which may be made with considerable accuracy for thicknesses of quartz not much in excess of $20 \mathrm{~mm}$.

(2) For great thicknesses of quartz both images are very pale for all positions of the ocular nicol; consequently, the setting by the above criterion cannot be made accurately.

\section{Summary of Conclusions from Early Work.}

The findings of Kitao, Koenig and Brodhun, insofar as they bear on our present interest in the leucoscope, may be summarized as follows: ${ }^{14}$

(I) The setting of the ocular nicol ("leucoscope reading"), by a trichromatic observer, for the condition of closest approach to color match of the two images (neither image reddish with respect to the other) depends upon:

a. The thickness of quartz.

b. The observer.

c. The spectral distribution of energy of the source (color temperature).

(2) Color-blind as well as normal trichromatic observers may make a setting, their criterion being perfect rather than approximate color match; and, indeed, they can make the match with a much smaller quartz thickness than the trichromatic observer. They also find the setting to depend upon the quartz thickness and the source of light. ${ }^{15}$

(3) There may or may not be a systematic difference in the settings made by the two eyes of the same observer. ${ }^{16}$

(4) The personal equation in the leucoscope reading cannot be explained in terms of the Young-Helmholtz theory alone. ${ }^{17}$

(5) The personal equation in the leucoscope reading can be explained by assuming individual differences in the relative visi-

"In some cases the obvious modern interpretation of the conclusions of the original papers has been restated in modern terms.

${ }^{13}$ Brodhun: See Appendix II for reference.

${ }^{10}$ Kitao: Zur Farbenlehre, pp. 29-3I.

${ }^{17}$ Kitao: Zur Farbculehre, pp. 6 and 21. 
bility of radiant power. (Modern interpretation of Kitao's conclusions. ${ }^{18}$ )

(6) The leucoscope is a valuable instrument for the diagnosis of color-blindness. ${ }^{19}$

(7) The leucoscope is a valuable instrument for studying the spectral distribution or color temperature of incandescent solids. (Modern interpretation of the results of Koenig and Kitao. ${ }^{20}$,

(8) For a constant light source and the same observer, the rotation of the ocular nicol is approximately but not exactly a linear function of the thickness of quartz. ${ }^{21}$ (Koenig emphasizes the fact that the relation is not linear; but on plotting his data, ${ }^{22}$ it is found that the departure from a linear relation is not much greater than the experimental uncertainty.)

(9) Twenty millimetres of quartz is a suitable standard to use $\because$ for comparative observations on different light sources. ${ }^{23}$

\section{Limitations of Early W'ork.}

It will be noticed, in the section above, that, in order to present them cogently, it has been necessary to restate or interpret in modern terms the original conclusions of Kitao and Koenig. This is because concepts now current were not well formulated; and quantitative data now available did not exist when their papers were published. They could not correlate and formulate their results to the best advantage because of a lack of fundamental data and fundamental concepts of two kinds, viz.:

(I) Visibility of radiant power. ${ }^{24}$

(2) The spectral distribution of energy as a function of temperature-temperature scale for the complete radiator ("black body") and incandescent solids-color temperature. ${ }^{25}$ The very

${ }^{18} Z$ ur Farbenlehre, p. 21, and $A b$. Tok. Univ., 12, pp. 30-31.

${ }^{19}$ Rose.

Koenig: Centb. fuir Prak. Augenheilk., 8, pp. 375-377. Brodhun: Ann. der Phy. und Chem., 34, p. 918.

${ }^{20}$ Koenig: Ann. der Phy. und Chem., 17, pp. 1003-1008. Kitao: Abh. Tokio University No. I2, pp. 34-58.

${ }^{21}$ Koenig: Ann. der Phy. und Chem., I7, pp. IOOI-I002.

${ }^{22}$ Ann. der Phy. und Chem., I7, p. Ioor.

${ }^{23}$ Koenig: Amn. der Phy. und Chem., 17, p. 1004.

${ }^{24}$ Koenig's determination of visibility, the earliest that is now given any consideration, was not made until about I89o.

${ }^{25}$ Wien's distribution law was published in 1896 ; Rayleigh's, in 1900; Planck's, in 1900. The scale of color temperature has been established only in very recent years by Hyde and others.

Vol. IV, No. 6-30 
terms in which the results could have been most simply and instructively stated were lacking. It is interesting to notice how this lack of data and concepts prevented the consummation of this early work, and how when these data and concepts became available, the work had apparently been forgotten.

\section{Purpose and Scope of the Present Paper.}

The purpose of the present paper is to give an introduction to a modern treatment of the leucoscope in terms of knowledge now available. The experimental basis consists of leucoscopic observations on light sources of known temperature by three observers of previously known visibility, ${ }^{26}$ and not " color-blind." These observations were made under the following conditions and circumstances ${ }^{27}$ :

(I) The criterion for the leucoscope setting was that adopted by Koenig. ${ }^{28}$ viz. : An approximate match of color quality (hue and saturation) is made such that neither ficld can be recognized as reddish relative to the other. For the lower temperatures, this results in a nearly or quite perfect match of color quality; for the higher temperatures, one field is very pale blue, the other, very pale yellow. No attempt was made to match brilliance.

(2) One standard thickness of quartz, $20.000 \mathrm{~mm}$.. as recommended by Koenig ${ }^{29}$ for the comparison of different sources was used in all observations. (The correctness of this thickness was checked by comparing its measured rotation for homogeneous light with Lowry's tables. ${ }^{30}$ )

(3) Temperatures are referred to the color temperature scale of Hyde; ${ }^{31}$ and are expressed in degrees Kelvin (absolute tem-

${ }^{20}$ I. G. Priest, P. D. Foote and H. J. McNicholas. Visibility by Coblentz and Emerson, B. S. Sci. Pap. 303.

${ }^{27}$ For further details, see also II below.

${ }^{2 s}$ Ann. der Phy. und Chem., r7, p. 999.

${ }^{20}$ Ann. der Phy. und Chem., 17, p. 1004.

${ }^{30}$ Phil. Trans. Roy. Soc. A., 212, p. 287 ; year 1912-13.

${ }^{31}$ Only color temperatures between about $1700^{\circ}$ and $2400^{\circ} \mathrm{K}$ are referable directly to Hyde's scale as established by the Nela Research Laboratory. Light of spectral distribution corresponding to temperatures above $2400^{\circ} \mathrm{K}$ is obtained directly from gas-filled lamps and by rotatory dispersion as explained under II-2 below. Temperatures below $1700^{\circ} \mathrm{K}$ are from a small black body. Sec also II-2 below. 
perature), except in one figure, where degrees Centigrade are used.

(4) Each observer used only his right eye.

(5) One observer made many repeated observations at various times over a period of several months so as to test the constancy of reading. Another repeated his first calibration after a period of several months. The third made calibrations on two successive days.

(6) The observer's eye was protected from extraneous light by a closely fitting eye-shade.

The primary data are presented in the form of calibration curves of leucoscope reading against temperature, arranged so as to show the personal equation and its degree of constancy with time.

These data are discussed with regard to (I) precision, (2) the personal equation, (3) the variation of the personal equation with time, (4) possible use of the leucoscope as a pyrometer.

Two new fundamental laws of the leucoscope are then derived from these data, and stated in terms relating the leucoscope reading to the spectral distribution of light, i.e., to the spectral distribution of energy of the light source and the observer's relative visibility of radiant power.

As illustrative of the use of the instrument and without attaching any permanent value or importance to them (because of their preliminary nature), leucoscopic determinations of the color temperature of several sources are given, as well as a series of determinations of the apparent color temperature of sunlight at the earth's surface showing its diurnal variation.

II. APPARATUS AND METHODS USED IN THE PRESENT INVESTIGATION.

I. The Arons Chromoscope and Its $U$ se as a Leucoscope.

No leucoscope originally designed as such was available for this investigation. However, the Arons chromoscope ${ }^{32}$ is so designed that it may be used to make leucoscopic observations (with some disadvantages noted below). The essential parts of this instrument as used in this investigation are shown in Fig. I and explained in the accompanying key.

\footnotetext{
${ }^{32}$ Leo Arons. Ann. der Phy. (4), 39, pp. 545-568; 1912.
} 
In using this instrument as a leucoscope the Lummer-Brodhun cube (LB) is removed and the analyzing nicol (A) is replaced by the Wollaston prism (W). The principal optical parts, in order from the eye, are then: (I) the observing telescope, (2) the Wollaston prism (W), (3) the quartz plates $\left(Q_{1}-Q_{7}\right)$, and (4) the nicol, (P). The quartz plates, $Q_{\mathrm{I}}-Q_{\mathrm{IV}}$, do not function in the leucoscope, and are removed except that one of them is used in obtaining light corresponding to very high temperatures as explained below. Rotation of nicol, $\mathrm{P}^{\prime \prime}$, relative to nicol $\mathrm{P}^{\prime}$, serves to adjust the field to a comfortable working brilliance.

One sees, on looking into the instrument, two circular images due to the Wollaston prism. These images are each about $3^{\circ}$ in diameter and overlap about one-quarter the diameter of either. It will be noticed that this arrangement is the reverse of the order of parts in the original leucoscope in that the element producing the double image (the Wollaston prism, W) lies between the eye and the quartz instead of between the quartz and the source.

This results in the disadvantage that the images rotate as the Wollaston prism is rotated to make the leucoscopic match. A few observations indicate a possible small systematic difference between readings in opposite quadrants, that is, with the positions of the images reversed-the whole field of observation turned through $180^{\circ}$. All readings reported in this paper were made in the same quadrant and are therefore comparable, although their absolute significance may be questioned; that is, we may expect the same observer to obtain slightly different values with a properly designed instrument.

Another disadvantage is the overlapping of the images. This would be a very serious matter if brilliance (intensity) matches were involved, but is not very troublesome in making the matches of color quality, which is all that is done. These disadvantages, although not very serious, were only tolerated because it was not practicable to make promptly any better arrangement for this preliminary work. It may probably be assumed that the precision and accuracy with a properly designed instrument would be better than that found in this preliminary investigation. ${ }^{33}$

Leucoscopic readings, by the criterion of Koenig described above, were made by rotating the Wollaston prism with the

${ }^{33}$ It is now planned to have a new model instrument constructed in the Bureau of Standards instrument shop. 
Leucoscope and Application to Pyrọmetry. 457
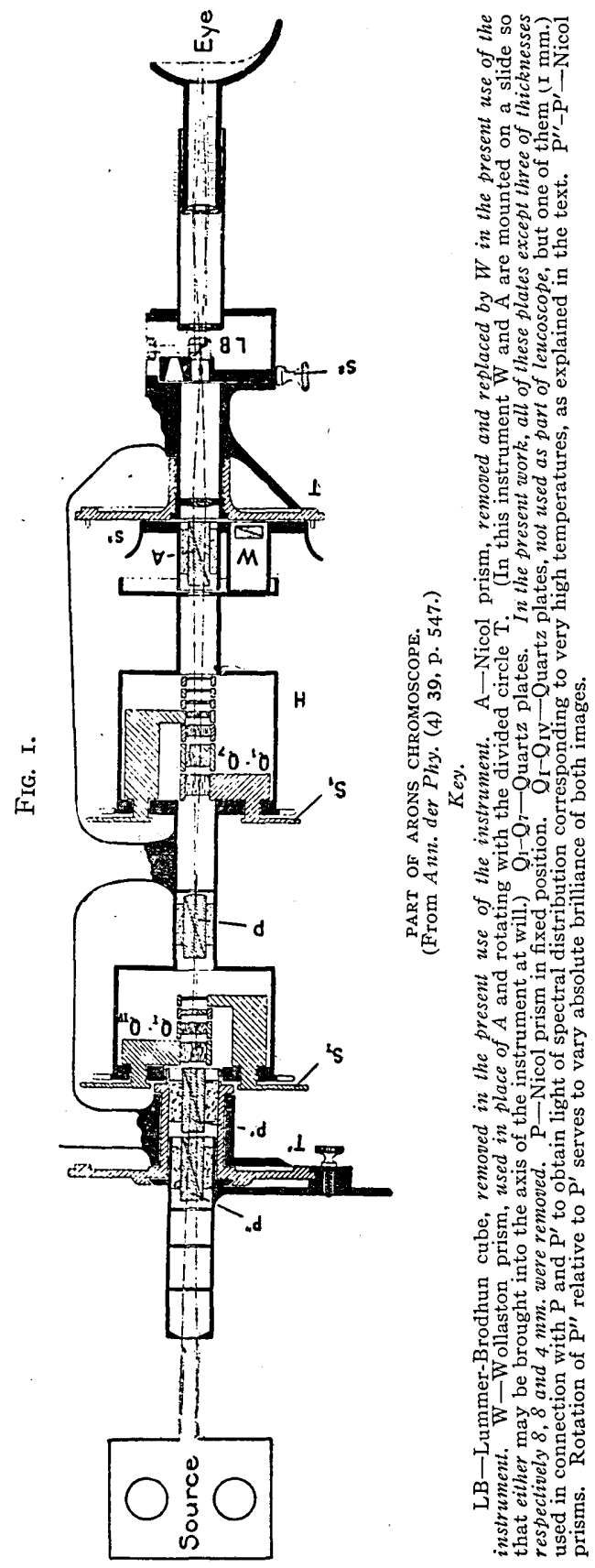
divided circle, $\mathrm{T}$ (Fig. I), in the same direction as the rotation of the plane of polarization by the quartz, angles being measured from zero for the extinction position of the extraordinary image

FIG. 2.

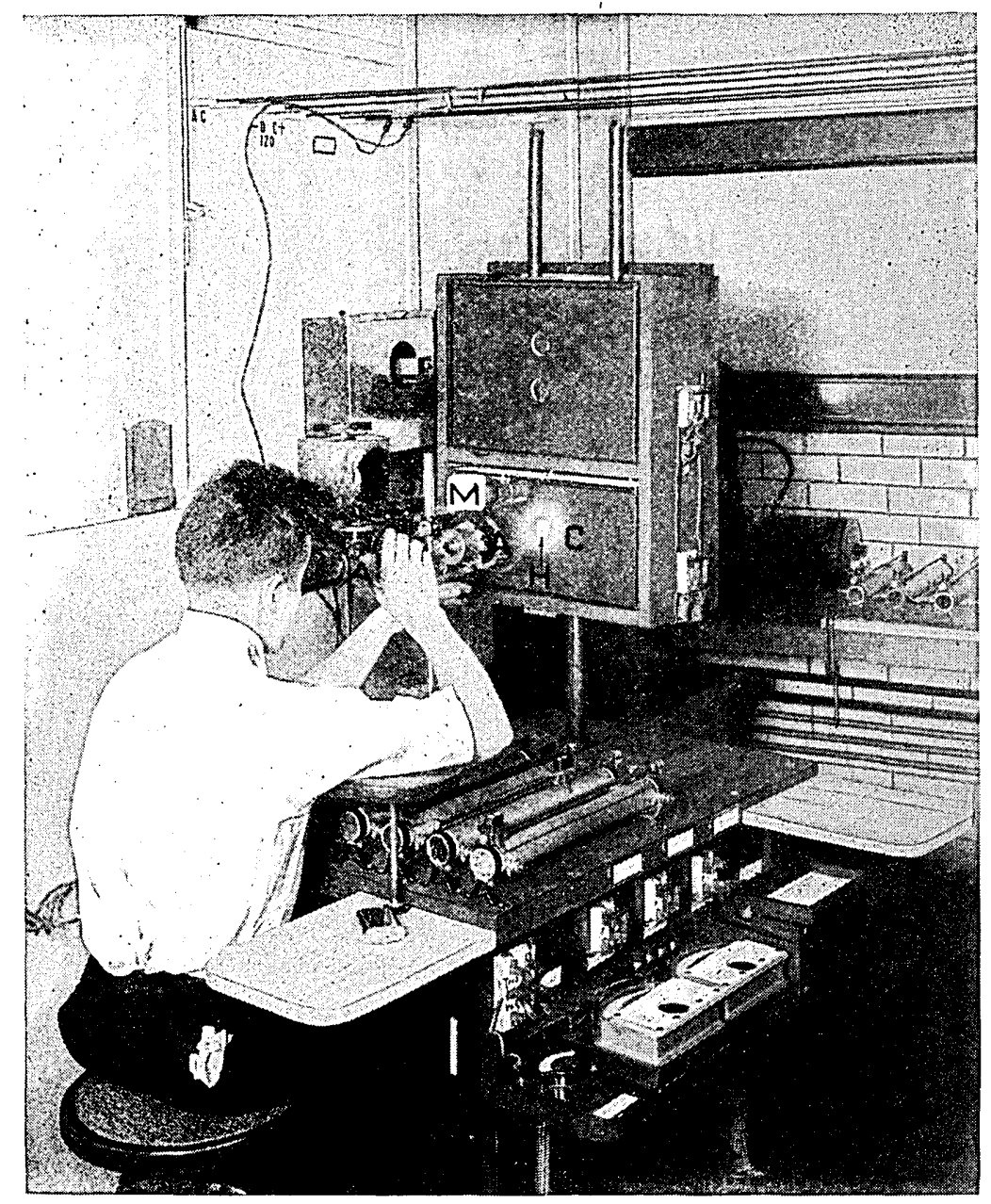

Assembled apparatus.

with all quartz removed. This angle is designated as the "leucoscope reading." (In reducing the results, care has been taken to correct for the small "zero error" of the circle.) . 


\section{Pyrometric Calibration-Temperature Scales.}

The pyrometric calibration has been made in part by pointing the instrument into a black body at measured temperatures and in part by pointing it at a magnesia surface illuminated by lamps at known color temperature. Care was taken to obtain a uniform field in each case. A single determination usually consisted of five observations. (In some cases only three, and in others, ten.)

The earliest quantitative observations of any reliability or importance were made on a small black body of the type used by Fairchild in the Bureau of Standards' pyrometric laboratory, ${ }^{34}$ and kindly loaned and operated for this purpose by Dr. Foote. Temperatures were read by Dr. Foote by means of a disappearing filament optical pyrometer immediately before and after each leucoscopic determination; and are estimated by him to be reliable to about $5^{\circ} \mathrm{C}$. However, this estimate of accuracy applies only to the measured brightness temperature for wavelength 650 millimicrons. We do not know how closely the small black body in question approximates to an ideal complete radiator, and therefore cannot state how closely these measured brightness temperatures should agree with color temperatures. With this source, a temperature range from about $800^{\circ}$ to $1600^{\circ} \mathrm{C}$ (II73 $1873^{\circ} \mathrm{K}$ ) was obtained (Fig. 5). To obtain higher temperatures standard incandescent filament lamps werel used, either directly or by an intermediate comparison source, and the observations made on the light reflected from a magnesium oxide or carbonate surface illuminated by the lamp.

A point at $2360^{\circ} \mathrm{K}$ was obtained by means of a vacuum tungsten lamp operated at a voltage previously determined to give a color match with a standard acetylene flame assumed to have this color temperature, as indicated by the most recent findings of Coblentz as well as those of Hyde, Forsythe and Cady. ${ }^{35}$

${ }^{3 *}$ This radiator was made of a sillimanite crucible within an outer crucible of alundum, the space between being filled with fused alumina. All sides except the aperture were heated electrically by a heater of platinum-rhodium wire. This furnace was cemented with alundum cement to give practically a one-piece furnace. It was supported on four porcelain legs about $15 \mathrm{~cm}$ long; and was freely exposed to the air. The dimensions were: inside diameter, $23 \mathrm{~mm}$; inside length on line of sight, $30 \mathrm{~mm}$; and aperture, $12 \mathrm{~mm}$.

${ }^{35}$ Hyde, Forsythe and Cady: Phy. Rev. (2), I3, pp. I57-158, I919; Phy. Rev. (2), 14, p. 379, 1919. Coblentz: Journ. Frank. Inst., pp. 399-401 ; September, 1919. B. S. Sci. Pap. 362, Feb., 1920. 
A point at $2830^{\circ} \mathrm{K}$ was obtained by means of a gas-filled tungsten lamp (B. S. Lamp i7I7) of known spectral energy distribution, previously determined radiometrically by Dr. W. W. Coblentz. The color temperature, $2830^{\circ} \mathrm{K}$, was derived as follows:

(I) The ratio of energy at wave-length 480 millimicrons to energy at wave-length 680 millimicrons was computed for a complete radiator (Planck's equation $c_{2}=1435^{\circ}$ ) for various temperatures, and plotted as a function of temperature.

(2) The same ratio for this lamp was found from Coblentz's data, and the corresponding temperature read from the graph just mentioned.

FIG. 3.

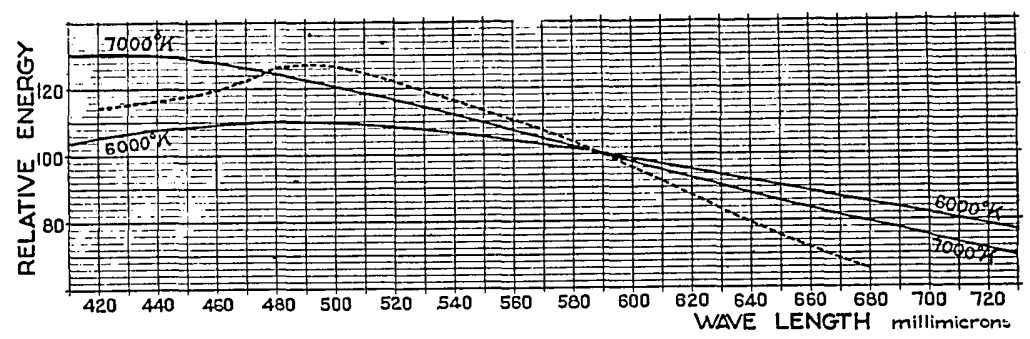

Comparison of Spectral Energy Distributions of Complete Radiator at $6000^{\circ}$ and $7000^{\circ} \mathrm{K}$ with Spectral Distributions Obtained by Method of Rotatory Dispersion. Actual source: B. S. lamp i 7 I6 at I 44. I volts, 22 1.p.w.

Quartz thickness $=1.000 \mathrm{~mm}$. $\phi=4.5^{\circ}$ (see Appendix I).
Solid curves: complete radiator by Planck's formula ( $\left.\mathrm{C}_{2}=1.435\right)$ for $6000^{\circ}$ and $7000^{\circ} \mathrm{K}$.

Dotted curve: B.S. lamp I 76 at 144 .I volts, modified by rotatory dispersion. Relative energy of lamp $x \sin ^{2}\left(4 \cdot 5-a_{\lambda}\right)$ (see Appendix I).

The points at $3000^{\circ}, 3200^{\circ}, 4000^{\circ}, 5000^{\circ}$, and $7000^{\circ} \mathrm{K}$ were obtained by the artifice of rotatory dispersion, a system consisting of a quartz plate between nicols being inserted between the source and the leucoscope so that the optic axis of the quartz is coincident with the line of sight. The effect is briefly this: Owing to the rotatory dispersion, the nicols and quartz plate constitute, in effect, a selective light filter, the spectral transmission of which is determined by the thickness of the plate and the angle between the principal planes of the nicols. ${ }^{36}$ It is pos-

${ }^{30}$ Cf. Arons: Ann. der Phy. (4), 33, rp. 8ro-819, year igro. Priest: Phy. Rev. (2), Io, pp. 208-212, year I917; Phy. Rev. (2), II, p. 502, year I918; Phy. Rev. (2), I5, pp. 538-539, year I920; and forthcoming papers "The Application of Rotatory Dispersion to Colorimetry," . . . See also Appendix I, this paper. 
sible to choose this thickness and angle so as to make a blue filter which will reduce the actual known spectral distribution of a lamp at operable temperature, approximately to the spectral distribu1tion (by Planck's formula) of a theoretical black body at some assigned high temperature. To accomplish this end in the present instance, use has been made of nicols $\mathrm{P}^{\prime}$ and $\mathrm{P}$ and a $\mathrm{I}-\mathrm{mm}$. quartz plate at $Q_{I}-Q_{I V}$ (Fig. I ). The complete specifications are recorded in the legends to Fig. 6 . The point $7000^{\circ} \mathrm{K}$ is uncertain because the energy distribution obtained is not strictly that of a black body (Fig. 3 ). The quantitative significance of the points at $3000^{\circ}, 3200^{\circ}, 4000^{\circ}$, and $5000^{\circ} \mathrm{K}$ may also be questioned because of the uncertainty of spectral distribution of energy in the standard acetylene flame, ${ }^{37}$ on which they depend (Cf. legend, Fig. 6). The distribution given by Coblentz and Emerson ${ }^{38}$ was first assumed. The resultant spectral distributions have now been recomputed assuming the spectral distribution of a complete radiator at $2360^{\circ} \mathrm{K}$ (Planck's $c_{2}=\mathrm{I} 435^{\circ}$ ) for the acetylene flame. The resultant distributions on both assumptions are compared with the theoretical (Planck's formula, with $c_{2}=I 435^{\circ}$ ) distributions in Fig. 4. On account of these uncertainties, no very definite significance can be ascribed to the calibration above $2830^{\circ} \mathrm{K}$. It will be noticed, however, that, in spite of these circumstances: (I) a smooth calibration curve has been obtained (Fig. 6); (2) the uncertain part is consistent with a reasonable extrapolation of the more certainly established part (Fig. 6); (3) the high temperature calibration is consistent with a reasonable assumption for the color temperature of noon sunlight at the earth's surface (Cf. Section. VI and Fig. I5, below); (4) the ligh temperature calibration is consistent with a reasonable assumption for the temperature of the sun itself (Cf. Sec. VI, below); (5) the calibration at about $3700^{\circ} \mathrm{K}$ is consistent with the probable temperature of the electric arc. (See Sec. IV-5, below.)

In the present state of uncertainty regarding both the spectral distribution of the acetylene flame and the value of Planck's constant, $c_{2}$, it does not appear worth while to discuss this ques-

${ }^{37}$ Cf. Hyde, Forsythe and Cady: Phy. Rev. (2), 13, pp. 157-158, r919; Phy, Rev. (2), I4, p. 379, 1910. Coblentz: Jour. Frank. Inst., pp. 399-40I, Sept., 1919; B. S. Sci. Pap. No. 362 , Feb., I920.

${ }^{38}$ Bull. B. S., ז3, p. 363 ; year 19r6. 


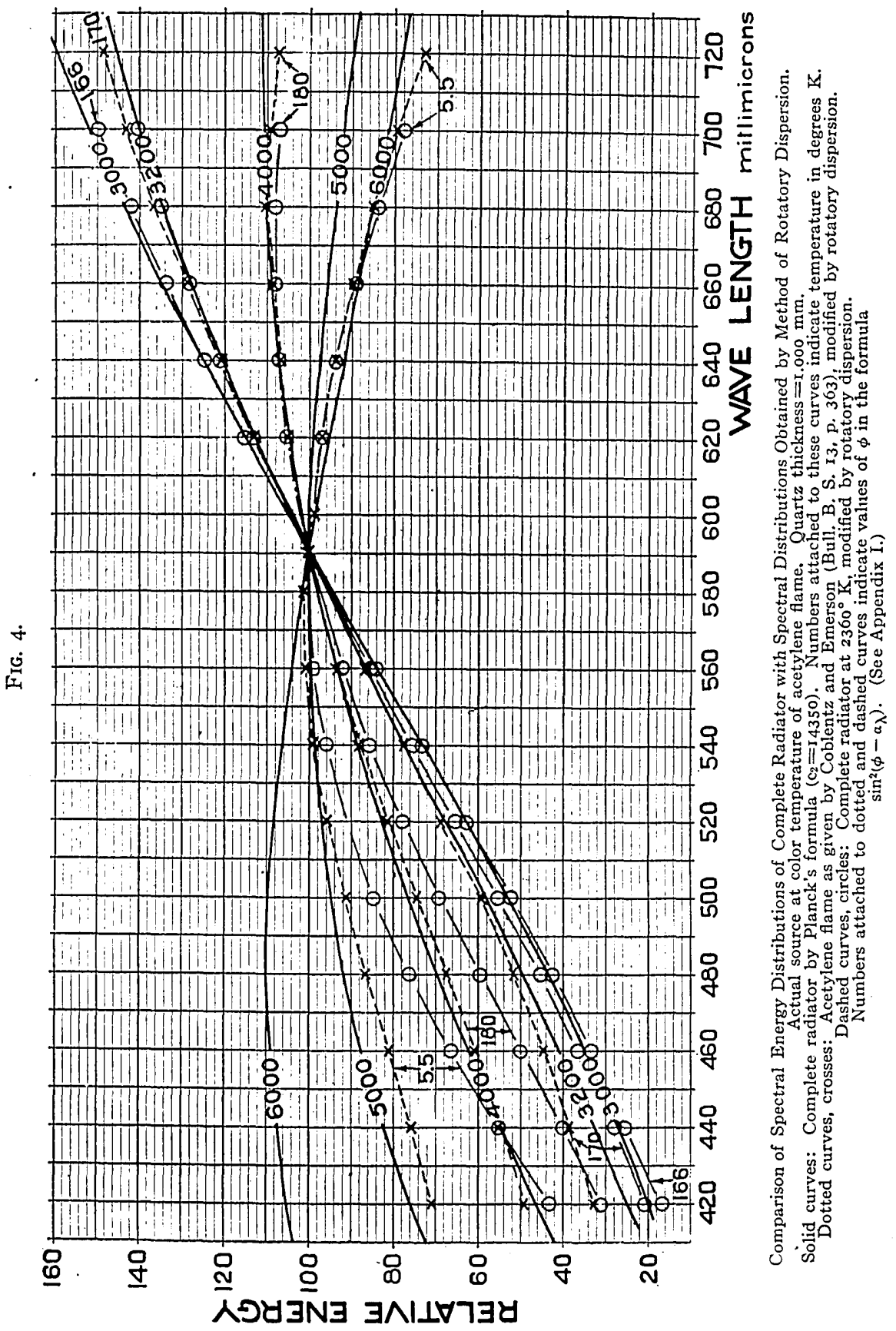


tion further. The calibration curve given (Fig. 6) is probably as significant as can be determined under the present circumstances; and it is considered worth while to publish it as a preliminary roughing out of the complete leucoscope-temperature function for an approximately normal observer for all temperatures between about $1000^{\circ}$ and $7000^{\circ} \mathrm{K}$.

Probably the most reliable part of the pyrometric calibration is that based on a standard vacuum tungsten lamp supplied by the Nela Research Laboratory, ${ }^{39}$ and certified by that laboratory to operate at given color temperatures, between $\mathrm{I} 700^{\circ}$ and $2400^{\circ} \mathrm{K}$, when maintained at prescribed voltages. This lamp was used as a standard both directly and indirectly. It was first determined that the selective reflection of a particular block of magnesium carbonate was negligible for this purpose. In the observations of April I, I920 (Fig. 7), this magnesium carbonate block being viewed by the leucoscope was illuminated directly by this standard lamp at various voltages, giving a series of color temperatures at which leucoscopic readings were made. This arrangement did not give sufficient light for accurate observations at low temperatures. To overcome this difficulty and to save the standard lamp, the following indirect method was adopted in later work: The standard lamp (at or near S, Fig. 2) illuminated a surface of the magnesium carbonate block placed so (M, Fig. 2) that the reflected light illuminated part of the Arons chromoscope (A, Fig. 2) field by means of the Lummer-Brodhun cube (LB, Fig. I ). ${ }^{40}$ All of the quartz plates $\left(Q_{1}-Q_{7}\right.$ and $Q_{1}-Q_{1 v}$, Fig. I) being removed, the other part of the field was illuminated by light reflected through the hole $\mathrm{H}$ (Fig. 2), from the magnesium oxide coated interior wall of the box C (Fig. 2), the interior of this box being illuminated by two seasoned vacuum tungsten lamps in parallel. The room was darkened and the block shaded so that no appreciable light other than that from the standard lamp fell upon the magnesium carbonate surface. With this arrangement, the standard lamp was operated at the voltages prescribed to give certain color temperatures ( I 7 I9, I849, I965, 2070, 2164, 2250, 2331, 2409 $\mathrm{K}$ ). The current in the lamps in the box, C (Fig. 2), was then adjusted to

${ }^{39}$ Letter and Report on Calibration, Nela Research Laboratory to Bureau of Standards, March 8, I920.

${ }^{40}$ Cf. also Arons: Ann. der Phy. (4), 39, p. 545. 
give a color match. This calibration of the current in the comparison lamps in terms of color temperature of the standard lamp was repeated many times by the author with different arrangements of the photometric field; and an average calibration curve plotted. It was also checked at $2360^{\circ} \mathrm{K}$ to within $8^{\circ}$ by the means of numerous observations on another Nela standard lamp. Subsequent calibration of the leucoscope was made by observations on the magnesia-coated wall of the box, C, with the comparison lamps in this box, operating at measured currents; and corresponding color temperatures were obtained from the current-temperature calibration curve just mentioned. The observations of August 25-26, I920, by Foote, McNicholas and Priest (Fig. 7), were made in this way. The chief advantage of this procedure over direct use of the standard lamp is that greater brightness in the leucoscope can be obtained, which is necessary at the low temperatures.

III. EMPIRIC RESULTS OF PYROMETRIC CALIBRATION.

The two calibrations, January 29 and 30 , I920, made with the small black body (about $800-1600^{\circ} \mathrm{C}$ ) and covering the range of industrial furnace temperatures, are shown in Fig. 5. The complete calibration for various temperatures from data obtained between January 29 and February 4, I920, is shown in Fig. 6. In Fig. 7 are shown:

( I) Calibrations based on the Nela standard lamp as follows:

a. By Priest, April I, August 25 and August 26, I920.

b. By Foote, April I, August 25 and August 26, I920.

c. By McNicholas, August 25 and August 26, I920.

d. Summarized data by Priest at $2000^{\circ} \mathrm{K}$. (Mean of all observations, July 8, 9, I2, I6, shown in detail in Table I.)

(2) Summarized previous data by Priest on other sources, obtained between January and August, I920. (The January-February data have already been shown in Fig. 6, but are reproduced here for the sake of comparison.) 
Leucoscope And Application to Pyrometry. 465

In order to exhibit in detail the precision and the reproducibility of the readings of a practiced observer from time to time, Tables I and II are presented. These data probably represent the most consistent work that can be done by this observer with the present apparatus, but not necessarily the best that could

FIG. 5 .

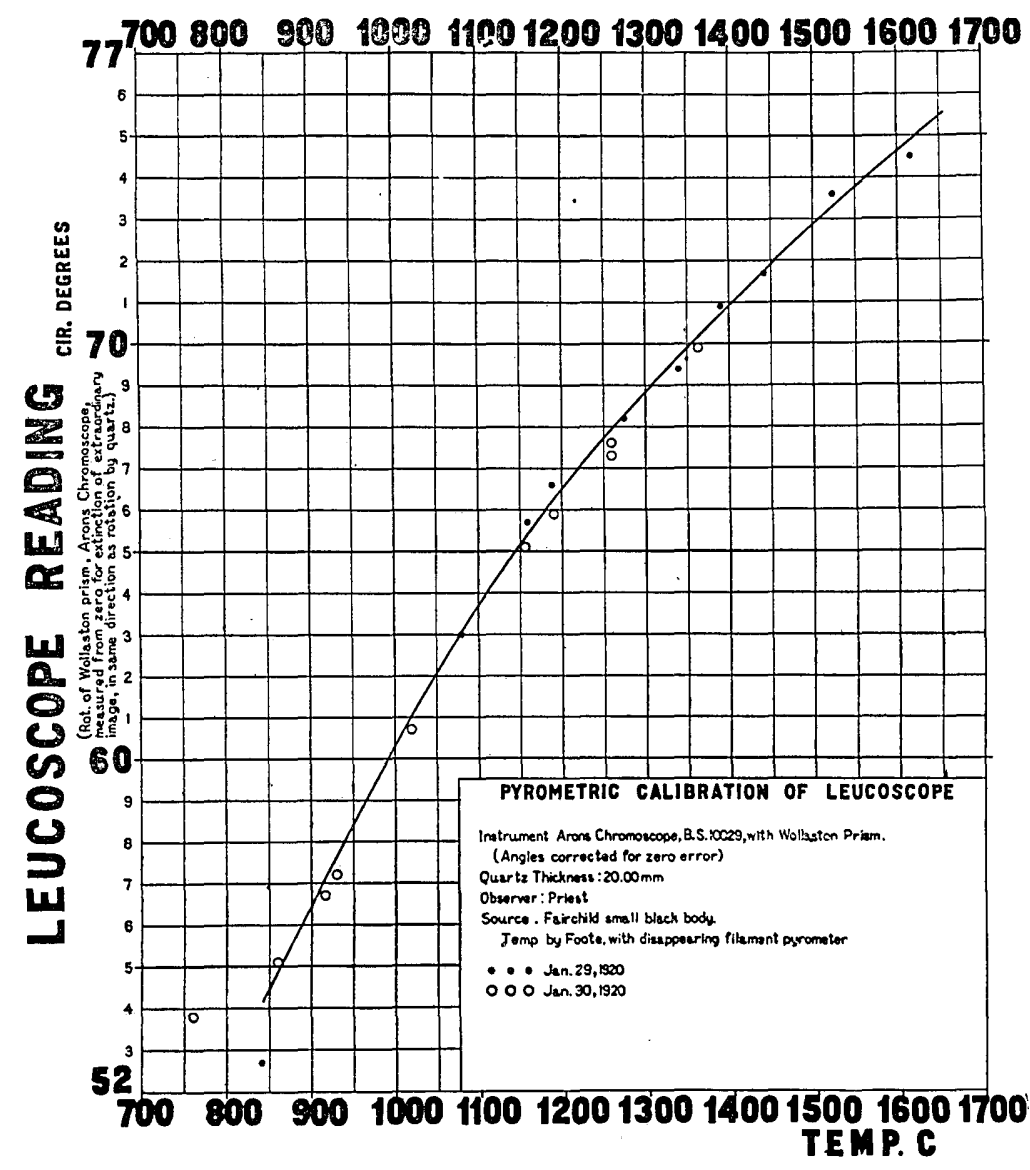

be done with a more favorably designed instrument. ${ }^{41}$ These data refer to two temperatures, namely, $2000^{\circ}$ and $2830^{\circ} \mathrm{K}$. Independent of any question as to whether or not these are true temperatures on any scale, they were accurately repro-

${ }^{41} \mathrm{Cf}$. discussion of disadvantages of instrument under II above. 


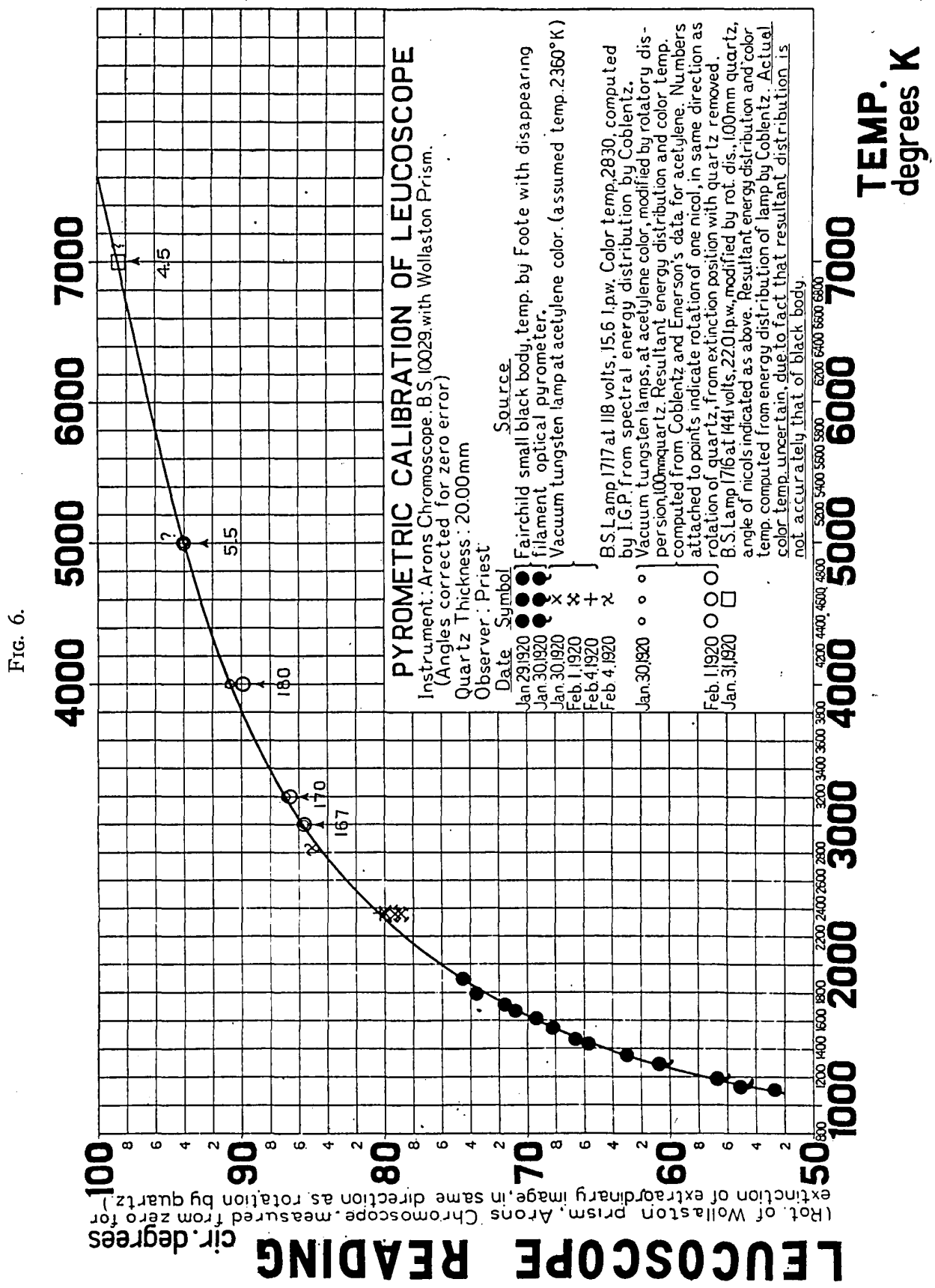


duced from time to time by reproducing the measured currents in the lamps, the whole arrangement of leucoscope, lamps, and accessory apparatus remaining undisturbed during the period

FIG. 7.

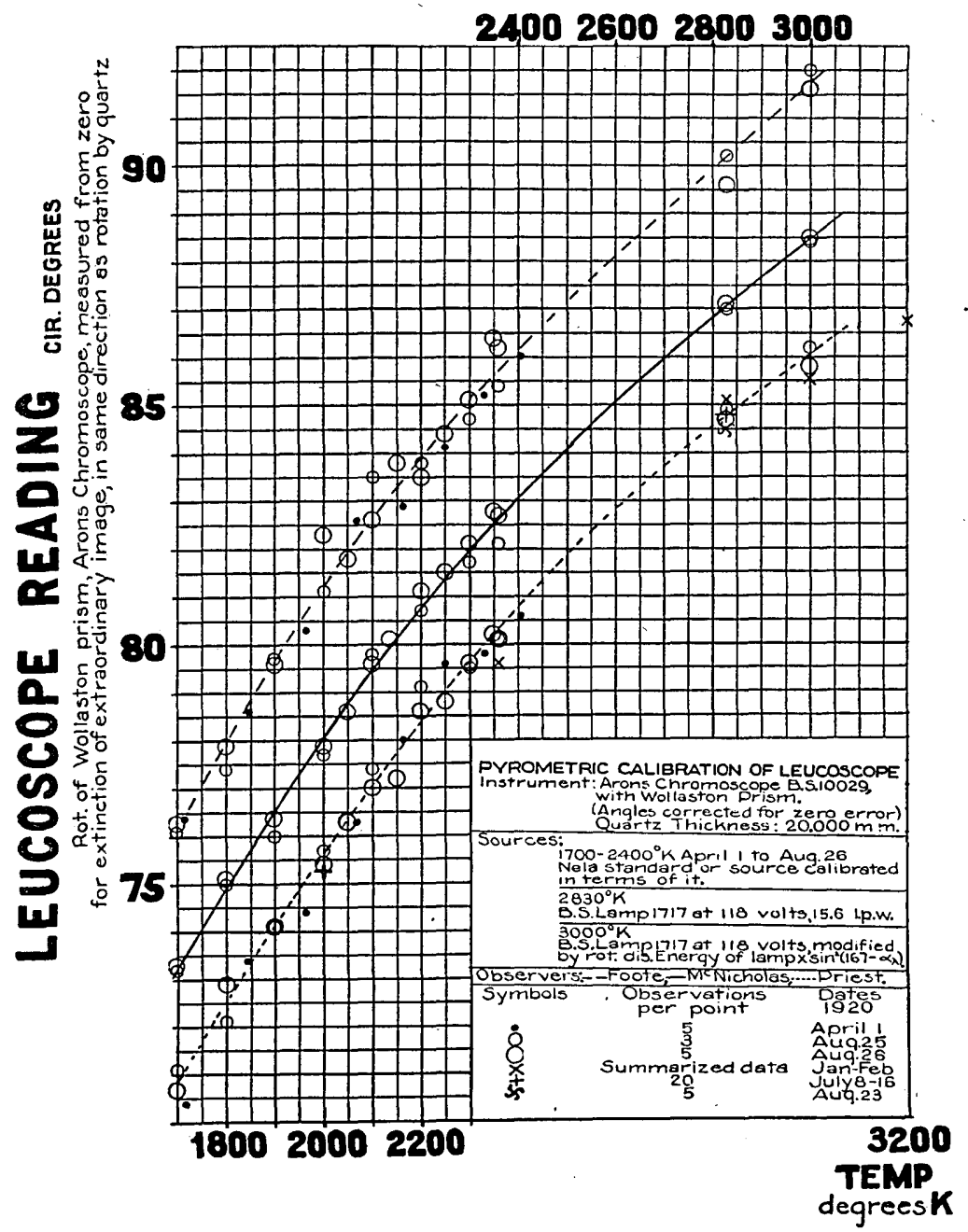

of these observations. The consideration of these data thus affords us a pure test of the reproducibility of one observer's readings at fixed points on the temperature scale. (Constancy of the personal equation.) 


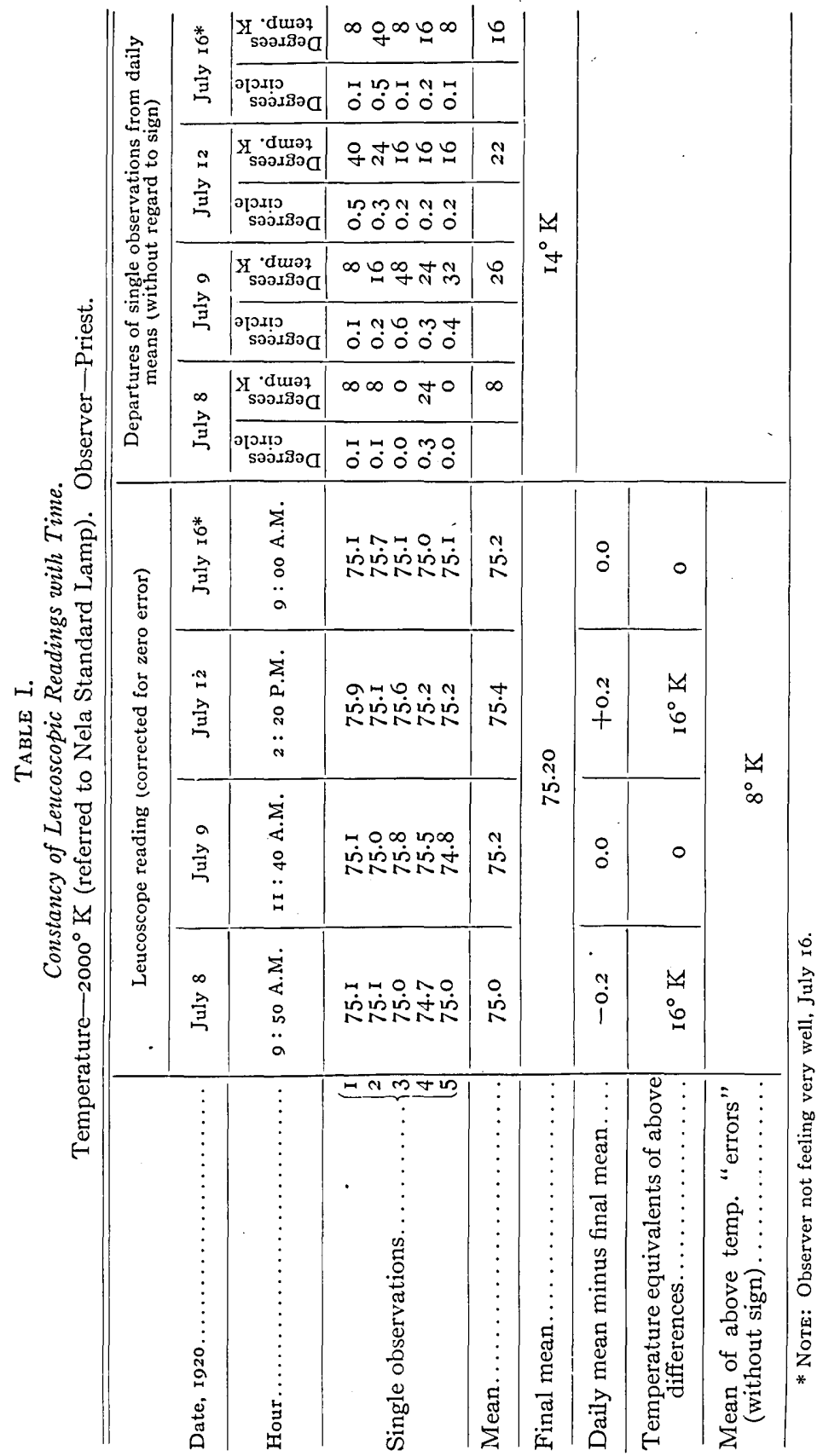


Leucoscope and Application to Pyrometry. 4.69

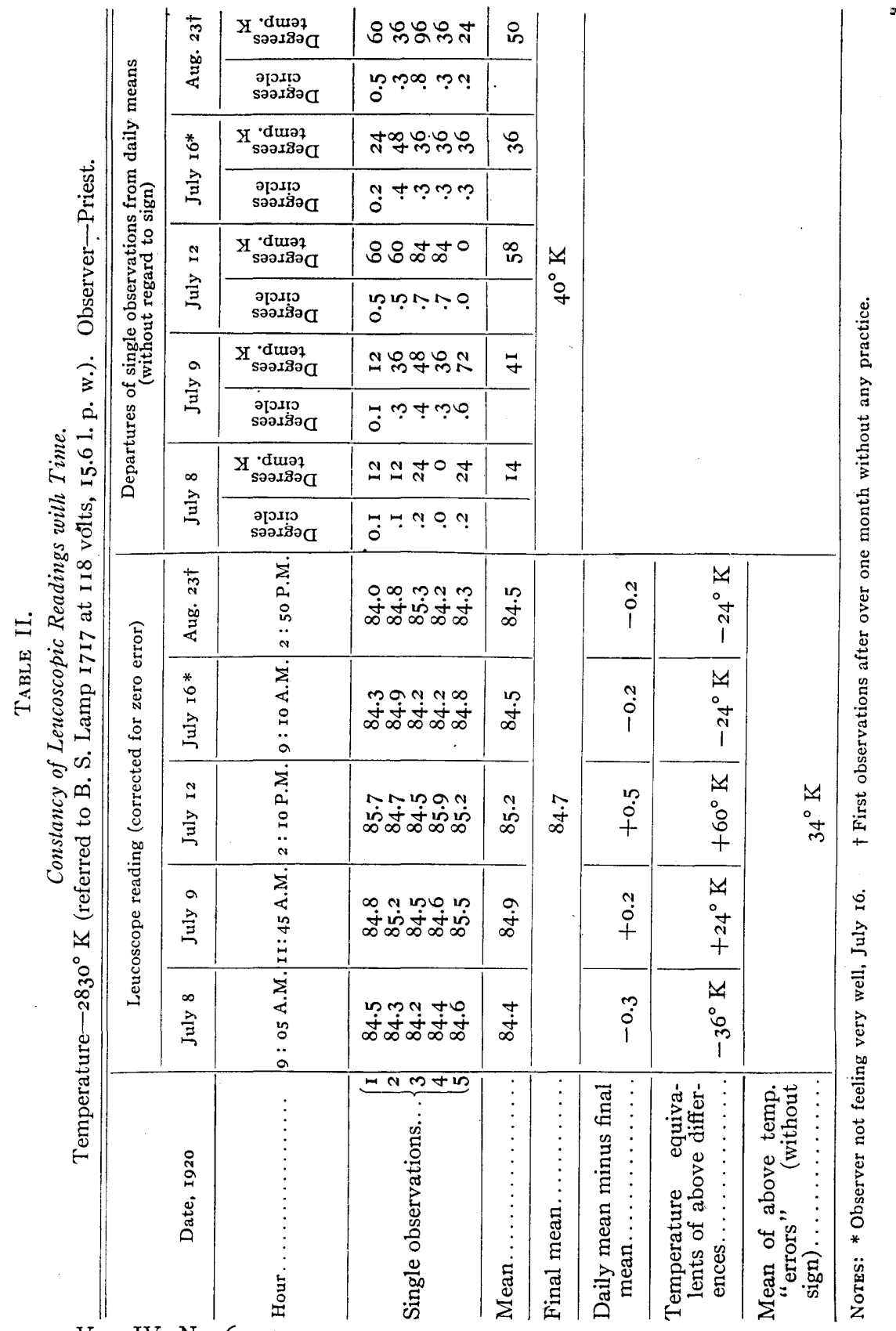

VoL. IV, No. 6-3I 
IV. DISCUSSION OF THE EMPIRIC RESULTS AS TO PYROMETRIC ACCURACY.

\section{Precision.}

The following estimates of precision of reading (agreement of observations made in rapid succession) are made from the early work done in January and February, 1920. The precision with a properly designed instrument would probably be better.
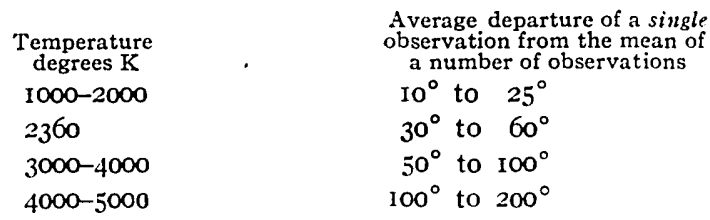

The reader may study the precision at two temperatures $\left(2000^{\circ}\right.$ and $2830^{\circ} \mathrm{K}$ ) in cletail from Tables I and II, from which the following may be concluded:

$\begin{array}{ccc}\begin{array}{c}\text { Temperature } \\ \text { degrees K }\end{array} & \begin{array}{c}\text { Average departure of } \\ \text { single observation } \\ \text { from mean }\end{array} & \begin{array}{c}\text { Maximum departure } \\ \text { of single observation } \\ \text { from mean }\end{array} \\ 2000 & 8^{\circ} \text { to } 26^{\circ} & 48^{\circ} \\ 2830 & 14^{\circ} \text { to } 58^{\circ} & 96^{\circ}\end{array}$

It will be noticed that the precision falls off notably with increasing temperature. This would appear, however, to characterize measurements of color temperature generally, rather than the leucoscope particularly. The reason for it lies in the fact that the quality of color changes much less rapidly with temperature at high temperatures than at low temperatures. The basis of this is apparent in the graphs in Figs. 9 and 10.

\section{The Personal Equation.}

The pyrometric calibration curves of three different observers will be found in Fig. 7. These three observers represent rather extreme types of visibility among non-colorblind individuals. The visibility curves of these observers taken from Coblentz and Emerson's original plots are shown in Fig. 8. The classification of their relative visibilities according to Coblentz and Emerson ${ }^{42}$ is as follows: Foote, subnormal blue; McNicholas, normal; Priest, subnormal red.

A marked personal equation is clearly shown, the differences

${ }^{12}$ B. S. Sci. Pap. 303, pp. $184-185$. 
between the different observers' readings at all temperatures $\left(1700^{\circ}-3000^{\circ} \mathrm{K}\right)$, being many times the uncertainty of any one observer's reading. ${ }^{43}$

\section{The Constancy of the Personal Equation at Different Times.}

From the agreement of observations on different days and at different hours as shown in Figs. 5, 6, and 7 and Tables I

FIG. 8.

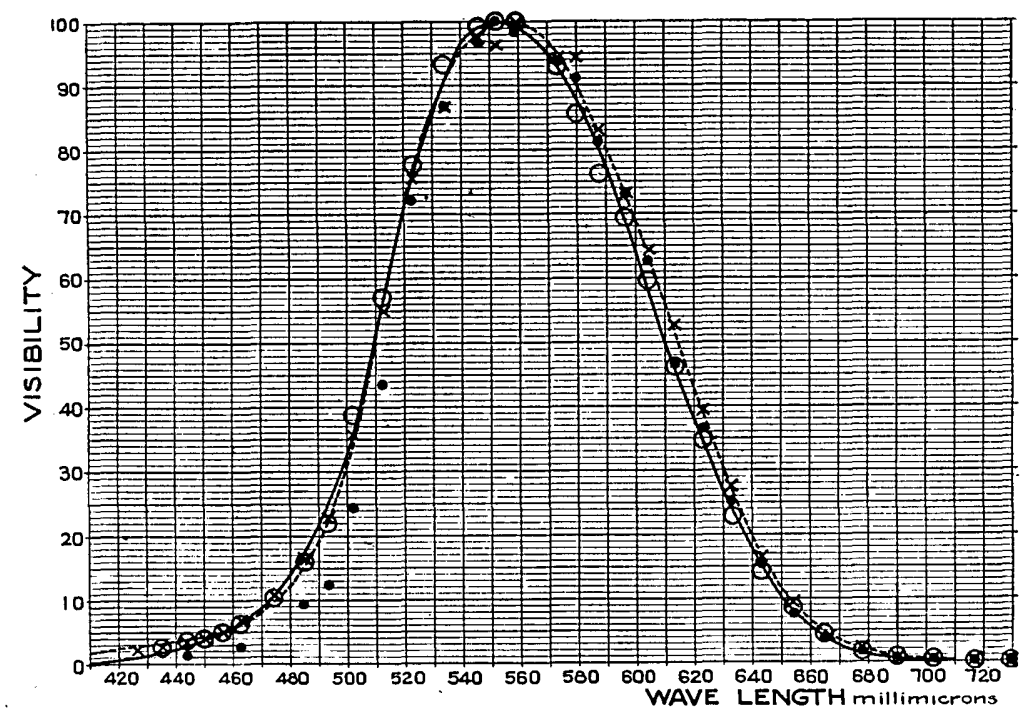

Relative Visibility of Radiant Power.

Solid curve: Average data adopted as standard in this paper. 400-550 and 660-7 Io millimicrons, Hyde, Forsythe \& Cady, Astrop. J. 48, p. 87. 560-650 millimicrons, Ives, Phil. Mag. Dec., I9I 2, Dashed curve: Coblentz and Emerson's av. 859.

Solid circles: Foote
Crosses : McNicholas $\left\{\begin{array}{l}\text { Data by } \\ \text { Coblentz and Emerson } \\ B . S . S c i . \text { Pap. 303, } \\ \text { Op. I84-I85. }\end{array}\right.$

and II, we conclude that the personal equation is constant, that is, that the change of reading from hour to hour, day to day, and month to month does not exceed the uncertainty indicated by the

${ }^{43}$ Similar calibrations for a number of observers of known visibility have just been completed with the same apparatus by C. M. Blackburn under the author's direction. Time has not yet been available to reduce and fully study these data. They will be published later. In the meantime, we refrain from attempting to make any correlation between the personal equations of visibility and leucoscope reading. 
differences between closely successive readings. It will be noticed that the observations on which this conclusion is based extend over several months and include work in both morning and afternoon. Some of the observations were made in a dark room, others in daylight.

Kitao found that previous fatigue by:

$$
\begin{aligned}
& \text { (a) spectral red, green or violet, } \\
& \text { (b) spectral red and violet (purple), } \\
& \text { or (c) "white light," }
\end{aligned}
$$

did not affect the leucoscope setting; while similar previous fatigue by other homogeneous stimuli destroys the color match and makes any setting temporarily impossible. ${ }^{4+}$ In the present investigation, no special tests of the effect of previous fatigue were made; nor were any precautions taken to bring the eye to any particular state; the observers were subject to ordinary laboratory conditions. It will be noticed from the record in Tables I and II that a slight disorder in the observer's health produced no effect in the reading, and it is further to be emphasized that the observer does not lose his criterion for the leucoscopic setting through a long period of disuse. (See Fig. 7 and Table II. Compare data of August 23 with July data, Table II. In Fig. 7, note that Dr. Foote made no observations between April I and August 25.)

\section{Total Uncertainty of Tempcrature Reading from a Calibra- tion Curve.}

This discussion is based on the data shown in Fig. 7 (Cf. Sec. III above) as follows:

(I) Small black dots, each representing the mean of five immediately successive observations, April I, 1920, by Foote and Priest.

(2) Small open circles, each representing the mean of three immediately successive observations, August 25, I920, by Foote, McNicholas, and Priest.

(3) Large open circles, each representing the mean of five immediately successive observations, August 26, 1920, by Foote, McNicholas, and Priest.

"Zur Farbenlehre, pp. 21-29. 
Foote is a skilled observer of long experience in optical pyrometry; but has made scarcely any leucoscopic observations other than those shown in Fig. 7.

$\mathrm{McNicholas}$ is a skilled photometrician of exceptional precision; but had made absolutely no leucoscopic observations prior to those shown for August 25 .

Priest's experience with the leucoscope dates from the latter part of January, 1920 , and is fully shown in this paper.

The point $x$ at temperature $2360^{\circ} \mathrm{K}$ is not strictly comparable with the data in April and August because different standard sources were used.

Dispensing with any mathematical adjustment, curves judged by appearance to represent these data about as well as possible have been drawn as follows:

Dashed curve, Foote's calibrations, April I, August 25, 26.

Solid curve, McNicholas' calibrations, August 25, 26.

Dotted curve, Priest's calibrations, April I, Aug. 25, 26.

The individual readings of the three observers are so far apart that there is no chance of confusing their respective data in the plots.

Taking the departure of each point from the curve, we find the following average and maximum departures:

\begin{tabular}{|c|c|c|}
\hline Foote & $\begin{array}{r}\text { Average } \\
25^{\circ} \mathrm{K}\end{array}$ & $\begin{array}{r}\text { Maximum } \\
75^{\circ} \mathrm{K}\end{array}$ \\
\hline McNicholas & $13^{\circ}$ & $45^{\circ}$ \\
\hline Priest $\ldots .$. & $20^{\circ}$ & $5^{\circ}$ \\
\hline
\end{tabular}

Omitting consideration of the points determined by only three observations, that is, considering only those determined by five observations, we find the following maximum departures:

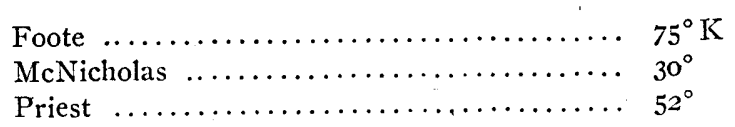

We conclude that,

The average error of a leucoscopic determination of temperature at about $2000^{\circ} \mathrm{K}$, based solely on color quality (i.e., paying no attention to equating brilliance) and derived from five observations by a qualified observer from his own calibration curve is about $15^{\circ} C$, and that the actual error rarely attains $50^{\circ}$ C. At lower temperatures, throughout the range of indus- 
trial furnace temperatures, the uncertainty aill be less than this. There has been as yet no opportunity to study thoroughly the reproducibility of readings at these lower temperatures.

\section{Possible Practical Use of the Leucoscope as a Pyrometer.}

It is evident from what has preceded that the leucoscope may be regarded as a type of optical pyrometer. Indeed, it has the distinction of being a strictly and purely optical pyrometer, requiring no electrical or other accessory apparatus. It shares this distinction with the sensitive tint pyrometer of Mesure and Nouel ${ }^{45}$ of which it may perhaps be considered a special case. The only essential difference in the design of the two instruments is that Mesure and Nouel substitute a nicol for the double image rhomb. ${ }^{46}$ This results in the observer's seeing only one uniform field instead of two juxtaposed fields to be compared and matched according to a stated definite criterion. (Cf. I-2 above.) The criterion for setting is only the so-called "sensitive tint" which must be carried in the observer's memory, and which changes with temperature. According to LeChatelier, Boudouard and Burgess, ${ }^{47}$ as well as the experience of the Pyrometry Section, Bureau of Standards, ${ }^{48}$ the Mesuré and Nouel instrument is of little value as a pyrometer. It would appear, a priori. highly probable that the leucoscope design would give much better accuracy than that of Mesure and Nouel because of the more definite criterion it affords. Some data as to the accuracy of leucoscopic temperature measurements have been given just above; but final judgment on the value of the leucoscope as a pyrometer should. not be based on this evidence alone. It is highly probable that a considerably higher degree of accuracy can be attained with a properly designed instrument (Cf. II-I above), particularly in

${ }^{45}$ LeChatelier and Boudouard: "High Temperature Measurements," English translation by Burgess, New York, I901, pages $158-160$. Burgess and LeChatelier: "High Temperature Measurements," page 348, New York, 1912.

${ }^{10}$ In the only Mesure and Nouel instrument which the author has examined, the thickness of quartz is about II $\mathrm{mm}$. This would be sufficient to use in leucoscopic observations; but is probably not the most favorable thickness (about $20 \mathrm{~mm}$.).

As a pyrometer, the leucoscope might with some reason be called the "duplex or double image sensitive tint pyrometer."

${ }^{47}$ Loc. cit.

${ }^{48}$ Information to the author from Dr. P. D. Foote. 
the range of industrial furnace temperatures. The author ventures to predict that, within this range, with such an instrument, by making and taking into account the readings for both the quality and brilliance match, temperature determinations from the mean of five observations may be made with an uncertainty of not more than 5 to $10^{\circ} \mathrm{C}$. The leucoscope appears to be worthy of careful consideration and study as a pyrometer. If it should prove to possess sufficient accuracy for even a limited number of purposes, its convenience and portability would recommend its wide use. On this score, it is only necessary to say that a complete instrument could be inclosed in a rectangular carrying case not more than $10 \times 10 \times 30 \mathrm{~cm}$, giving a total weight probably less than 2 or 3 pounds; and that absolutely no electrical or other accessory apparatus would be required for its use.

Without attaching any special importance to them, the following leucoscopic determinations of temperature made by the author on the basis of the calibration curves in this paper are given for comparison with previous data:

\begin{tabular}{|c|c|c|c|c|}
\hline Source & $\begin{array}{c}\text { Leucoscope } \\
\text { Reading } \\
\text { (cir. degrees) }\end{array}$ & $\begin{array}{l}\text { Temperature } \\
\text { from } \\
\text { Calibration }\end{array}$ & & Previous Values \\
\hline Kerosene flame (flat) & $\begin{array}{l}\text { 76.I } \\
\text { (Mean of } 20 \\
\text { observa- } \\
\text { tions) }\end{array}$ & $\begin{array}{c}2035^{\circ} \mathrm{K} \\
\text { (From Cal. } \\
\text { Fig. 7) }\end{array}$ & 2045 & Hyde and Forsythe (Jour. \\
\hline Paraffin candle.... & $\begin{array}{l}73.9 \\
\text { (Mean of ro } \\
\text { observa- } \\
\text { tions) }\end{array}$ & $\begin{array}{l}\text { I890 (From } \\
\text { Cal. Fig. 7) }\end{array}$ & 1920 & $\begin{array}{l}\text { Frank. Inst., 183, pp. } \\
353^{-354)} \text {. }\end{array}$ \\
\hline Crater, carbon arc. . & $\begin{array}{l}89.6 \\
\text { (Mean of } 5 \\
\text { observa- } \\
\text { tions) }\end{array}$ & $\begin{array}{l}3720 \text { (From } \\
\text { Cal. Fig. 6) }\end{array}$ & $\begin{array}{l}3690 \\
3680 \\
3720\end{array}$ & $\left\{\begin{array}{l}\text { Various determinations of } \\
\text { black body tempera- } \\
\text { ture, by Waidner and } \\
\text { Burgess (Bull. B.S., I, } \\
\text { p. I23). }\end{array}\right.$ \\
\hline
\end{tabular}

The following possible fields for the use of the leucoscope as a pyrometer suggest themselves :

(I) Temperature measurements of industrial furnaces where the utmost accuracy is not required.

(2) The color grading of incandescent light sources in terms of color temperature. ${ }^{49}$

${ }^{49}$ The author agrees with Hyde and Forsythe (Jour. Frank. Inst., I83, pp. $353-354$; 1917) that color temperature affords the most suitable basis for the color grading of illuminants. 
(3) Field measurements of the quality of daylight. (Cf. Sec. VI, below.)

(4) The color grading of stars in terms of color temperature. (Subsequent to a more careful calibration for high temperatures.)

\section{THE LAWS OF THE LEUCOSCOPE.}

I. The Relation between the Leucoscope Reading and the Spectral Distribution of Light from the Source.

The first law derived from the observations recorded in this paper may be stated as follows:

The leucoscope reading is a linear function of the angle through which the plane of polarization of the wave-length of the spectral centre of gravity of the light from the source ${ }^{50}$ is rotated by the quartz plate.

This relation has been arrived at by the following procedure:

(I) The spectral luminosity curves of a black body were drawn as shown in Fig. 9, on the basis of data as specified in the legend to that figure.

(2) The wave-lengths of centres of gravity of these curves were determined by a planimeter.

(3) These wave-lengths of centre of gravity were plotted against temperature as shown in Fig. Io.

(4) For selected temperatures (indicated in degrees $\mathrm{K}$ by numbers attached to circles in Fig. I I), the angular reading of the leucoscope was read from the calibration curve in Fig. 6 while the wave-length of centre of gravity for the same temperature was read from Fig. Io.

(5) The rotation of the plane of polarization for these latter wave-lengths by $20.000 \mathrm{~mm}$. of quartz was then obtained from a very accurate large scale rotatory dispersion curve based on Lowry's data. ${ }^{51}$

(6) The angular readings of the leucoscope were then plotted against these rotations as shown in Fig. I I.

(7) The locus of these points is found to be accurately a straight line (heavy solid line, Fig. II) throughout the range

${ }^{\text {so }}$ Centre of gravity or so-called "centre of area" of "luminosity curve" of the source.

"Phil. Trans. R. S., London, A, 212, pp. 288-289; year 1912-13. 
FIG. 9.

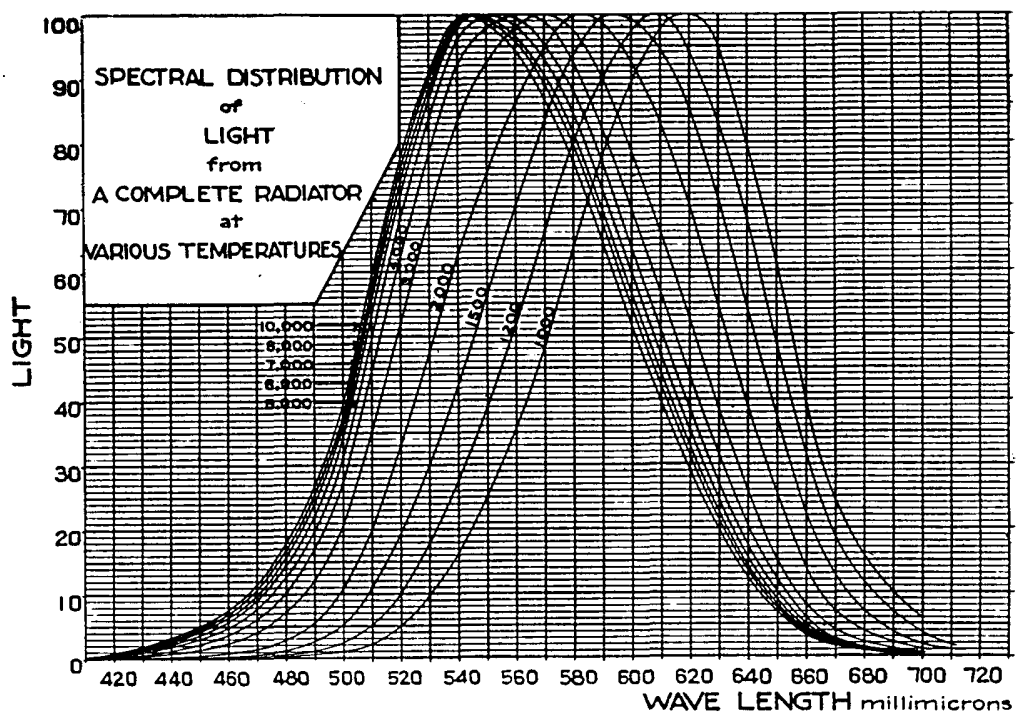

Spectral Distribution of Light from a Complete Radiator at Various Temperatures. Energy by Planck's formula $\left(c_{2}=14350\right)$.

Visibility: $\lambda, 560-650, \mathrm{H}$. E. Ives, Phil. Mag., Dec., I912, p. 859. $\lambda, 4$ ro-550 and 660-710, Hyde Forsythe \& Cady, Jour. Frank. Inst. 48, p. 87.

Numbers attached to curves indicate temperatures in degrees $\mathrm{K}$

FIG. ro.

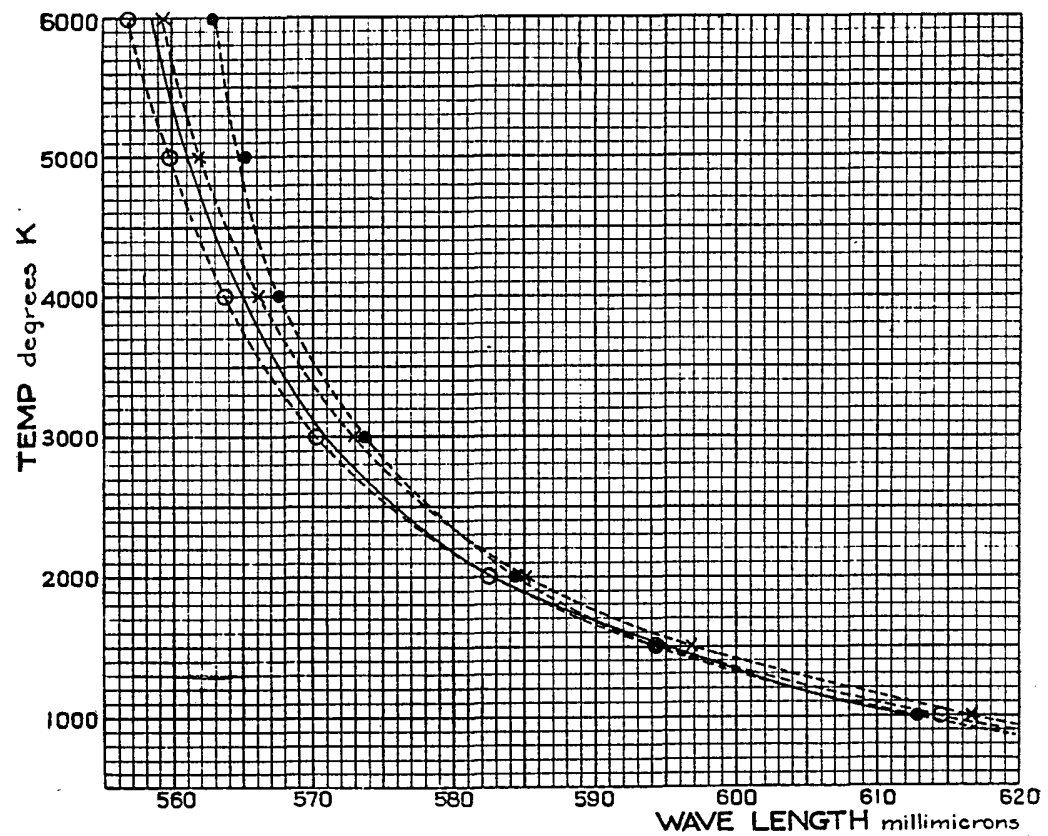

Relation of the Wave Length of Centre of Gravity of Spectral Distribution of Light to Temperature of the Source. Energy distribution by Planck's formula ( $\left.c_{2}=14350\right)$.

Visibility:- Solid curve: Average data, 400-550 and 660-710 millimicrons, Hyde, Forsythe \&

Cady, Astrop. J. 48, p. 87. 560-650 millimicrons, Ives, Phil. Mag., Dec., I91 2, p. 859. Solid circles: Foote (Data by Coblentz

Crosses McNicholas and Emerson,

Open circles: Priest 
unaffected by great uncertainties of observation and computation. It is impossible to say at present whether the deviations for temperatures less than $1250^{\circ} \mathrm{K}$ and greater than $4000^{\circ} \mathrm{K}$ are real or due to these uncertainties. This relation has been retested for the limited temperature range $1700^{\circ}$ to $3000^{\circ} \mathrm{K}$ by using the data

FIg. II.

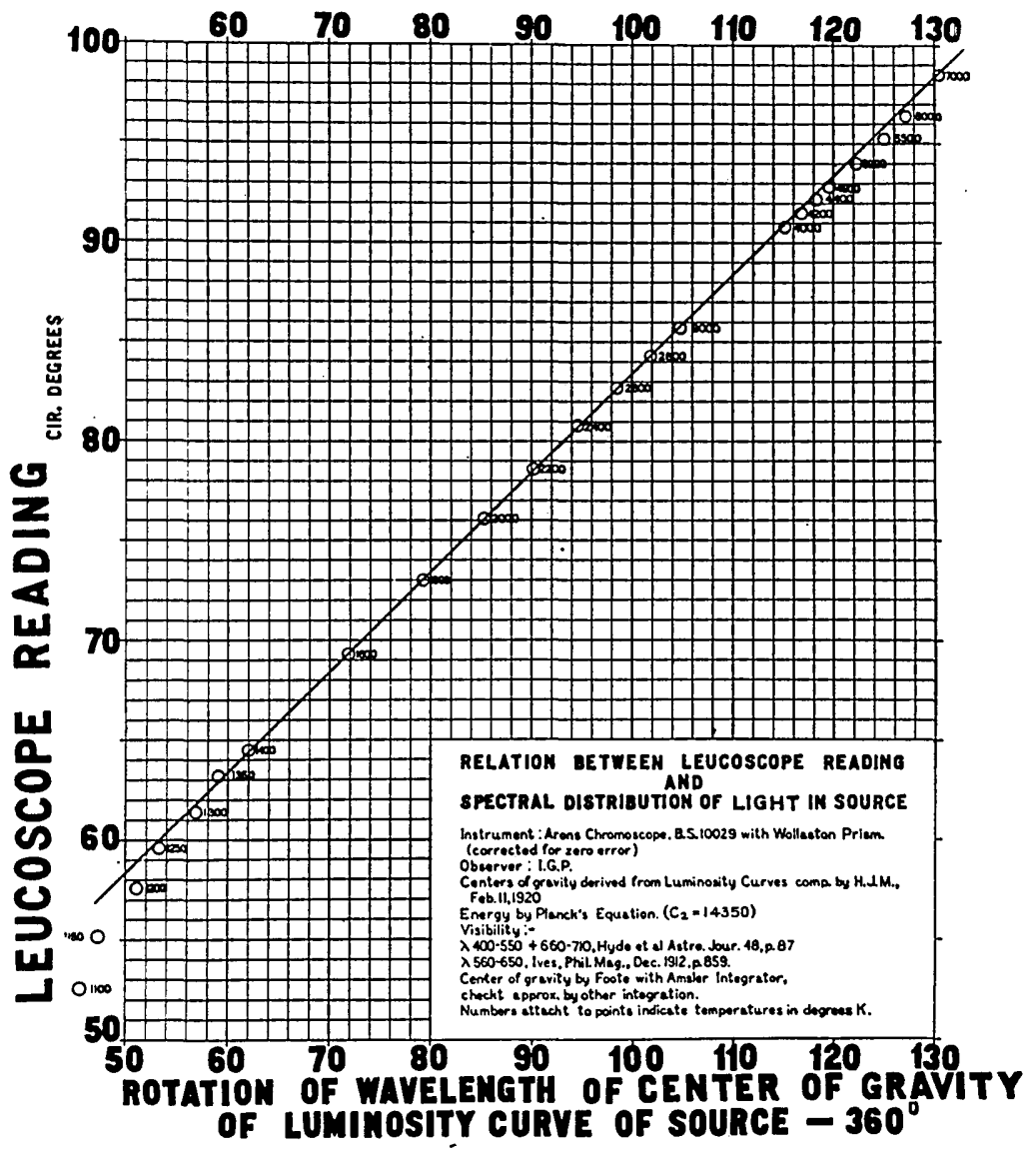

shown in Fig. 7. In this case the individual "luminosity curves" for each observer have been computed at different temperatures from his own visibility as given by Coblentz and Emerson. ${ }^{52}$ The remaining steps of the reduction being carried through as outlined

${ }^{82}$ B. S. Sci. Pap., No. 303, pp. 184-185. 
just above, we obtain the graphs shown in Fig. I2, which is plotted in the same way as Fig. I I. It will be noticed that the relation is linear for each observer, but that both the slope and the intercepts depend upon the individual.

FIG. I2.

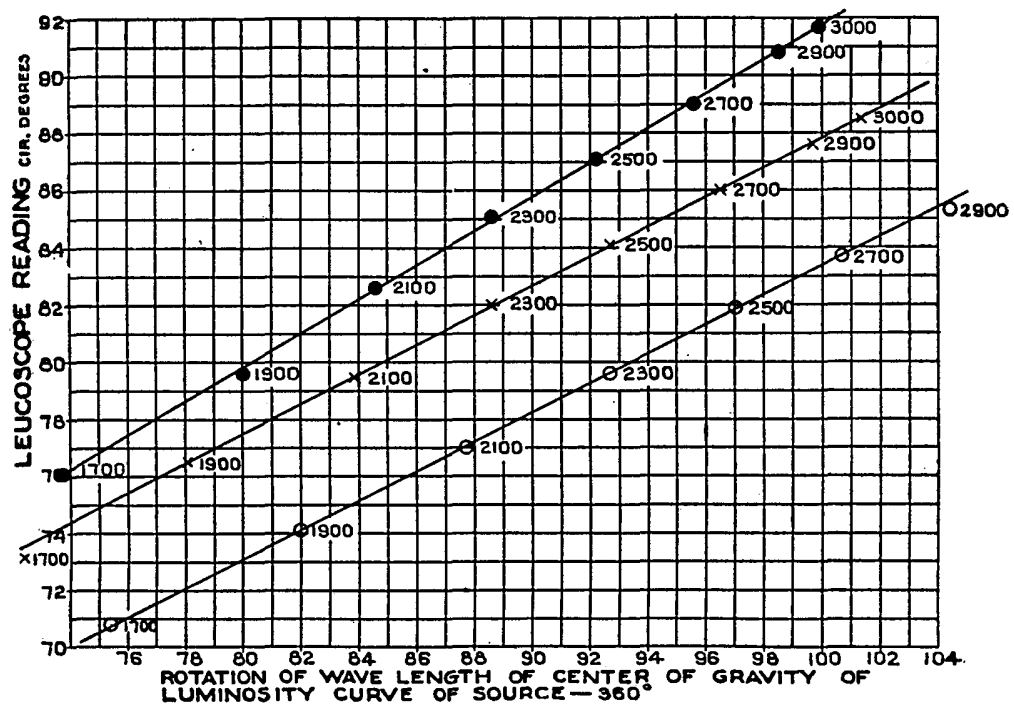

Relation Between Leucoscope Reading and Spectral Distribution of Light from the Source for Three Observers.

Solid circles: Foote.

Crosses: McNicholas.

Open circles: Priest.

Numbers attached to the points indicate temperatures in degrees $\mathrm{K}$.

2. The Essential Condition That is Satisfied in Making the Leucoscope Setting.

The second law derived from the observations recorded in this paper may be stated as follows:

The condition which is satisfied when the leucoscopic match is made according to Koenig's criterion is that the wave lengths of the spectral centres of gravity of the light of the source ${ }^{53}$ and the two images in the leucoscope are coincident or nearly so. ${ }^{54}$

${ }^{33}$ Centre of gravity or so-called "centre of area" of "luminosity curve."

${ }^{4}$ Cf. Priest: "Relation Between Quality of Color and Spectral Distribution," Jour. Op. Soc. Am., Sept., I020. 
This condition is illustrated for two particular temperatures, namely $2000^{\circ} \mathrm{K}$ and $3000^{\circ} \mathrm{K}$ in Figs. $\mathrm{I} 3$ and $\mathrm{I} 4$. The graphs in these figures represent, respectively:

I. Solid curve, spectral distributon of light (energy times visibility) for the given temperature, computed on the basis of Planck's equation (for $c_{2}=14350$ ) and visibility data as indicated in the legends of the figures.

2. Dashcd curve, spectral distribution of light in the extraordinary image in the leucoscope, computed by the formula :

(Planck's Function) ${ }_{\lambda}$ (Visibility) ${ }_{\lambda} \sin ^{2}\left(\phi-20 \alpha_{\lambda}\right)$ where $\phi=$ leucoscope reading.

$\alpha_{\lambda}=$ rotation of plane of polarization by one millimeter of quartz, for wave length, $\lambda$.

3. Dotted curve, spectral distribution of light in the ordinary image in the leucoscope, computed ${ }^{\text {ss }}$ by the formula:

(Planck's Function $)_{\lambda}(\text { Visibility })_{\lambda} \cos ^{2}\left(\phi-20 \alpha_{\lambda}\right)$.

The wave-lengths of the centres of gravity of these curves are as follows :

Temperature $2000^{\circ} \mathrm{K}$.

Extraordinary Image (relatively, slightly bluish) $\ldots \ldots \ldots \ldots 581.5 \mathrm{~m} \mu$

Black Body ................................ 582.6

Ordinary Image (relatively, slightly yellowish) $\ldots \ldots \ldots \ldots \quad 583.2$

Temperature $3000^{\circ} \mathrm{K}$.

Extraordinary Image (relatively, slightly bluish) $\ldots \ldots \ldots \ldots 568.9$

Black Body ............................. 570.8

Ordinary Image (relatively, slightly yellowish) $\ldots \ldots \ldots \ldots$ 571.9

VI. EXPERIMENTS ON LEUCOSCOPIC DETERMINATION OF THE QUALITY OF SUNLIGHT AND ITS DIURNAL VARIATION.

$\mathrm{My}$ average leucoscope reading for sunlight on a magnesium carbonate block, between I I o'clock and I o'clock, February 20, I 920 , at Washington, was about $94^{\circ}+$. Koenig gives $90.5^{\circ}$ for his observation on sunlight, ${ }^{\overline{5} \mathbf{6}}$ but records neither the date nor the hour of observation. This is approximately equal to my readings at 8 A.M. and 4:30 P.M. The higher latitude of Koenig's station (Berlin, Germany) would make his reading lower than

${ }^{s s}$ For computation of $\sin ^{2}\left(\phi-201 \alpha_{\lambda}\right)$ and $\cos ^{2}\left(\phi-20 \alpha \alpha_{\lambda}\right)$ see Appendix $\mathrm{I}$.

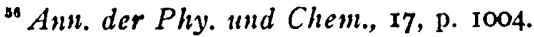


FIG. I3.

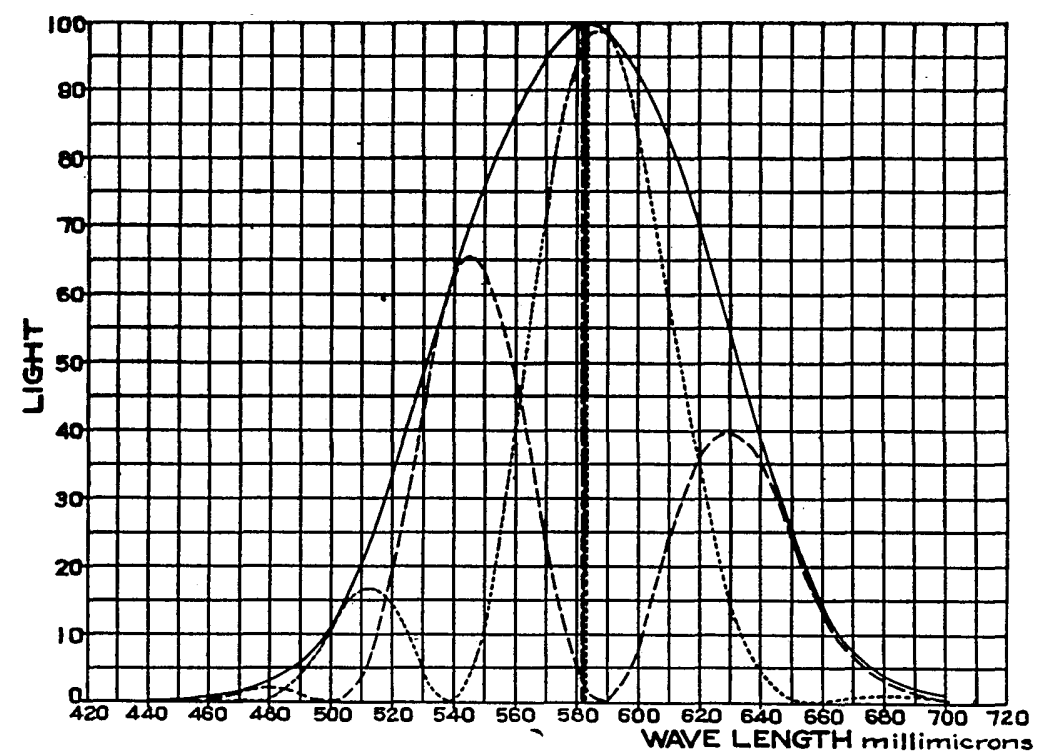

Spectral Distributions of Light in Leucoscope Images for Temperature $2000^{\circ} \mathrm{K}$.

Visibility: $\lambda, 560-650, H$. E. Ives, Phil. Mag. Dec., IOI 2, p. 850. $\lambda, 410-550$ and $660-7 \mathrm{IO}$ Hyde, Forsythe and Cady, A stro. Jour., 48, p. 87.

Solid curve: source, (Planck's function) $\times$ (visibility).

Dashed curve: extraordinary image, (Planck's function) $X$ (visibility) $\sin ^{2}\left(76.1^{\circ}-20 a\right.$, ).

Dotted curve: ordinary image, (Planck's function) $\times\left(\right.$ visibility) $\cos ^{2}\left(76.1^{\circ}-20 a_{\lambda}\right)$.

Vertiçal lines at about $\lambda=582$ indicate centres of gravity, solid, dashed and dotted having same significance as above.

FIG. I4.

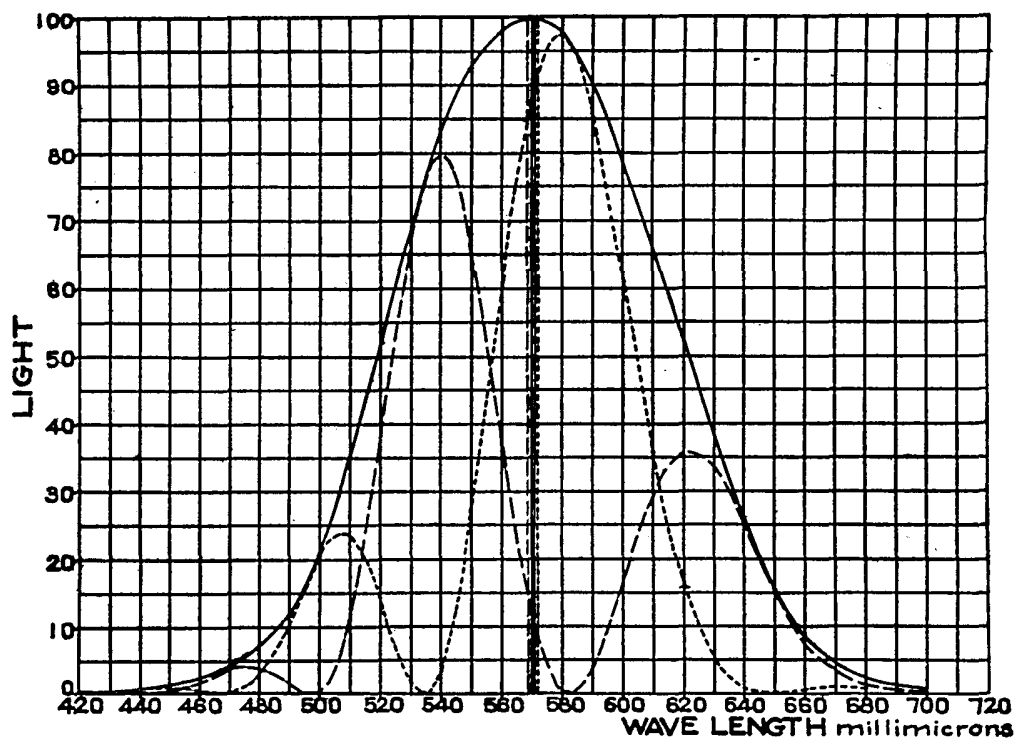

Spectral Distribution of Light in Leucoscope Images for Temperature $3000^{\circ} \mathrm{K}$.

Energy by Planck's formula (c2 $=14350)$.
Visibility : $\lambda, 560-650$, H. E. Ives, Phil. Mag., Dec., I9I2, p. $859 . \lambda, 410-550$ and 660-710, Hyde, Forsythe and Cady, Astrop. Jour. 48. p. 87.

Solid curve: source, (Planck's function) $\times$ (visibility).

Dashed curve: extraordinary image, (Planck's function) $\times$ (visibility) $\sin ^{2}\left(85.7^{\circ}-20 a_{\lambda}\right)$.

Dotted curve: ordinary image, (Planck's function) $\times$ (visibility) $\cos ^{2}\left(85.7^{\circ}-20 a_{\lambda}\right)$.

Vertical lines at about $\lambda=570$ indicate centres of gravity, solid, dashed and dotted having same significance as above. 
mine because of increased air mass, ${ }^{5 \pi}$ but there is really no basis for an accurate comparison because of the unknown relation of our personal equations.

In Fig. I 5 are shown one day's observations on the apparent color temperature of sunlight derived by means of the calibration curve shown in Fig. 6 from determinations with the apparatus described above. Each point plotted represents only a single observation. The observations above $4000^{\circ} \mathrm{K}$ are subject to an uncertainty of $100^{\circ}$ to $200^{\circ}$; but many of the deviations from a smooth curve may be real and due to changes in the atmosphere. Some of them were accompanied by large sudden changes in

FIG. 15.

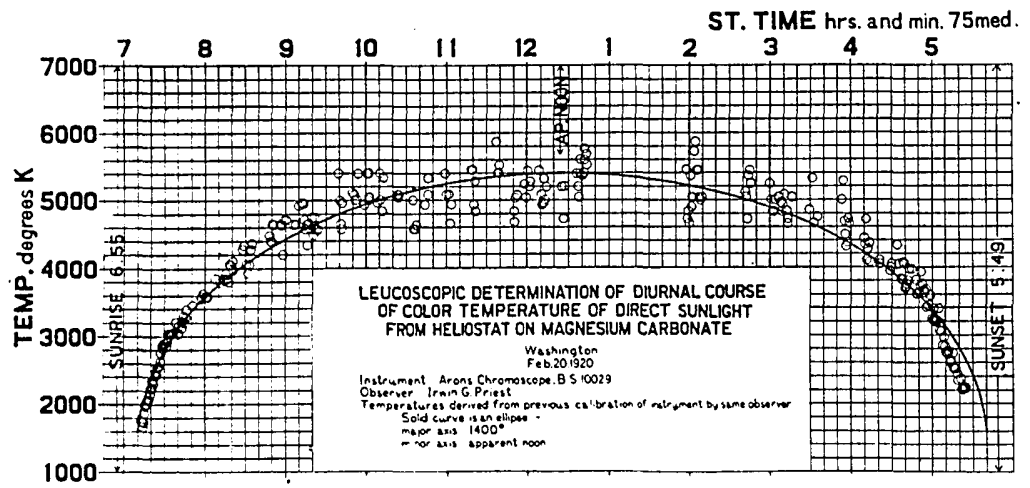

brightness. From these leucoscopic observations (Fig. I5) the apparent color temperature of sunlight at noon at the earth's surface in Washington in February appears to be about $5200^{\circ} \mathrm{K}$ to $5400^{\circ} \mathrm{K}$. H. E. Ives has selected $5000^{\circ} \mathrm{K}$ as representative of considerable previous data for average noon sunlight, ${ }^{58}$ while Abbot's data ${ }^{50}$ indicates approximately $6000^{\circ} \mathrm{K}$.

To ordinary casual and non-technical observation the whole day from shortly after sunrise to shortly before sunset appeared very clear, the sky being blue without any clouds. However, Dr. H. H. Kimball, of the Weather Bureau, reports that, on the basis of his pyrheliometer record, this was not a "good clay."

\footnotetext{
${ }^{37} \mathrm{Cf}$. discussion of Fig. 15, in third paragraph following this.

${ }^{5 s}$ Trans. I. E. S., April, 1910, p. 193.

${ }^{39}$ Priest: Phy. Rev. (2), II, p. 502, Fig. 1.
} 
"There was a great deal of haze in the atmosphere which made the pyrheliometer readings quite irregular." 60

Doctor Kimball has replotted the logarithms of these temperatures against air mass, and, extrapolating this curve to zero air mass, he finds $6500^{\circ} \mathrm{K}$ for the color temperature of the sun. The temperature of the sun hitherto derived by various methods appears to lie between $5800^{\circ} \mathrm{K}$ and $7000^{\circ} \mathrm{K} .{ }^{61}$ I would not attach any importance to the value found from my single day's observation; and give it merely to illustrate the use of the instrument.

Leucoscopic observations which I have made on daylight lead to the following conclusions:

(I) The quality of color of the densely overcast sky is very uniform in different directions; is subject to little diurnal variation (within 4 or 5 hours of noon); and is about the same as sunlight outside the earth's atmosphere. This conclusion is based upon the following values of color temperature derived from observations made by pointing the leucoscope (Arons chromoscope as described above) directly at the sky in Washington:

Date

Hour

Feb. 5, 1920 .... I2:50 P.M.

Feb. 5, I920 ..... I :00 P.M.

Feb. 5, 1920 .... 5:00 P.M.

Feb. 6, 1920.... 9:00 A.M. $60^{\circ}$ South from Zenith
Condition Temp. deof sky grees, $\mathrm{K}$

\section{Uniform} overcast. 6300 Mist.

$60^{\circ}$ North from Zenith Ditto 6500 $60^{\circ}$ South from Zenith Ditto 6500

\section{Uniform} overcast. 6500

Dense snowstorm.

(2) The difference in color of a horizontal non-selective surface illuminated by sun and sky together and by the sky alone is strikingly shown by the leucoscope. The following are color temperatures found under these circumstances at about 4 P.M., February I I, I920, the sky being blue with thin white clouds.

Sun and sky together $5700^{\circ} \mathrm{K}$

Sky alone 7400

\footnotetext{
${ }^{\circ}$ Letter, Kimball to Priest, Oct. I, I020.

as Smithsonian Physical Tables, 7th Ed. (year I920). Table 549. p. 4 I8.
} 
In considering the applicability of the leucoscope to field investigations of the color of sunlight and daylight, it is perhaps worth while to emphasize again the following features:-

(I) Its portability.

(2) The extreme rapidity with which observations can be made.

(3) The absence of any comparison source or accessory apparatus demanding the observer's attention.

\section{GENERAL SUMMARY AND CONCLUSION.}

This paper has given an account of a new study of the leucoscope from the point of view of its pyrometric calibration. The complete calibration curve from about $1000^{\circ}$ to $7000^{\circ} \mathrm{K}$ has been determined, at least approximately, for one observer; and more careful and accurate calibrations from $I 700^{\circ}$ to $2400^{\circ} \mathrm{K}$ have been determined for three observers. The questions of precision, personal equation, the reproducibility of observations at fixed temperatures and the practical application of the instrument to pyrometry and the color grading of light sources have been discussed rather fully. The possible utility of the instrument in industrial pyrometry, the color grading of light sources, and the study of the color of daylight has been pointed out and illustrations of its use given. Two new laws of the instrument have been formulated.

The applicability of the leucoscope to the study of color vision has been scarcely touched upon in this paper because the author believes it would be futile to discuss this phase of the subject without much more extensive statistical data on a large number of observers of known characteristics in regard to visibility, hue discrimination and color-blindness. It seems, however, that the data given in this paper should be of fundamental importance in elucidating the physiological theory of the leucoscope. It is not unlikely that the instrument would prove useful in the study of color vision, as was indeed long ago affirmed by Brodhun. ${ }^{62}$ However, observations of several color-blind observers recently conducted here by $\mathrm{Mr}$. C. M. Blackburn, show that these observers are quite unable to make any consistent observations, which appears to be entirely out of accord with Brodhun's findings. ${ }^{63}$ This

"Ann. der Phy. und Chem., 34, p. 918.

${ }^{63}$ Brodhun: Loc. cit., Appendix II, this paper. 
discrepancy may perhaps be due to our omission of making a brilliance match simultaneously with the color quality match. This question requires further investigation.

It is planned to publish data upon a number of other observers in a subsequent paper.

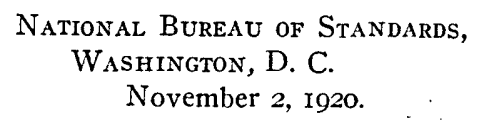

P. S. (Added to proof Dec. 3, I920).--Since writing the above the author has devised a much more accurate method of setting up the color temperature scale from $3000^{\circ}$ to $7000^{\circ} \mathrm{K}$ than that given in this paper (Sec. II, 2, and Figs. 3 and 4). This method will be described in a later number of this Journal under title: "A Method of Obtaining Radiant Energy Having the Spectral Distribution of a Complete Radiator at Very High Temperatures." Data on the actual spectral distribution of B. S. Lamp I $7 \mathrm{I} 7$ used in this paper as standard of color temperature at $2830^{\circ} \mathrm{K}$ will also be given in the forthcoming paper.-I. G. P.

\section{APPENDIX $\mathrm{r}$.}

The Computation of Spectral Transmission by Rotatory Dispersion.

If a crystalline quartz plate, with plane surfaces perpendicular to the optic axis, be placed between nicol prisms so that the optic axis is coincident with the line of sight through the nicols, the system so constituted is, in effect, a selective light filter of adjustable spectral transmission. The transmission is a function of :

(I) the wave length, $\lambda$;

(2) the thickness of the quartz plate, $b$;

(3) the angle through which one of the nicols is rotated relative to the other, in the same direction as the rotation of the plane of polarization by the quartz and measured from zero for the position of extinction with the quart\% removed, $\phi$.

The relative transmission is given by the formula:

$$
\sin ^{2}\left(\phi-b \alpha_{\lambda}\right)
$$

where $\alpha_{\lambda}=$ rotation by unit thickness of quartz for wave-length $\lambda$.

Voc. IV, No. 6-32 
The computation chart, Fig. 16 , has been prepared to facilitate the evaluation of this function for any value of $\phi$ and selected values of $\lambda$, for $b=1.000 \mathrm{~mm}$. Values of $\phi$ are plotted as abscissa and values of $\sin ^{2}\left(\phi-\alpha_{\lambda}\right)$ as ordinate. ${ }^{64}$ The scale at the bottom is to be used in connection with the scale on the left; and the scale at the top, with that on the right. Each curve in these figures relates to a particular value of $\lambda$, indicated in the margins by numbers attached to the curves by arrows. By use of this chart, the spectral curve showing the relative transmission of quartz-nicol systems such as used in this investigation to obtain spectral energy distributions corresponding to high temperatures may be quickly plotted. Such plots for selected values of $\phi$ are shown in Fig. 17.

If a calcite rhomb or double image prism (Wollaston) be substituted for one of the nicols, as in the leucoscope, the relative transmissions corresponding to the two images will be:

$$
\begin{aligned}
& \text { extraordinary image, } \sin ^{2}\left(\phi-b \alpha_{\lambda}\right) \\
& \text { ordinary image, } \cos ^{2}\left(\phi-b \alpha_{\lambda}\right)
\end{aligned}
$$

Figs. I 8 to 2 I (similar to Fig. I6) provide for evaluating these functions for the standard leucoscope quartz thickness of 20.000 $\mathrm{mm}$. In order to avoid confusion of the curves, it has been necessary to prepare four separate figures each covering a limited range of wave-lengths.

The method of using these charts (Figs. 16, I8, 19, 20, 21) should be sufficiently obvious without further explanation.

Curves of relative spectral transmission derived from these computation curves for $b=20.000 \mathrm{~mm}$. and selected values of $\phi$ (50, 6o, $70,80,90^{\circ}$ ) covering nearly our complete range of leucoscope readings are shown in Fig. 22. They will be of interest to those who care to analyze critically the action of the leucoscope.

For further treatment of the above subject, reference may be made to the following:

I. Koenig: Ann. der Phy. und Chem., 17, pp. 994-995.

2. Brodhun: Ann. der Phy. und Chem., 34, pp. 897-918, particularly Fig. 3.

3. Arons: Ein Chromoskop, Ann. der Phy. (4), 33, pp. 799-832; 1910.

4. Priest: Phy. Rev. (2), ro, p. 208, Aug., 1917; Phy. Rev. (2), Ir, p. 502, June, 1918. The Application of Rotatory Dispersion to Colorimetry (forthcoming paper.)

" Computed from Lowry's rotatory dispersion data, Phil. Trans., Roy. Soc., Loil. A., 212, pp. 288-289. 
Leucoscope and Application to Pyrometry.

FIG. I6.

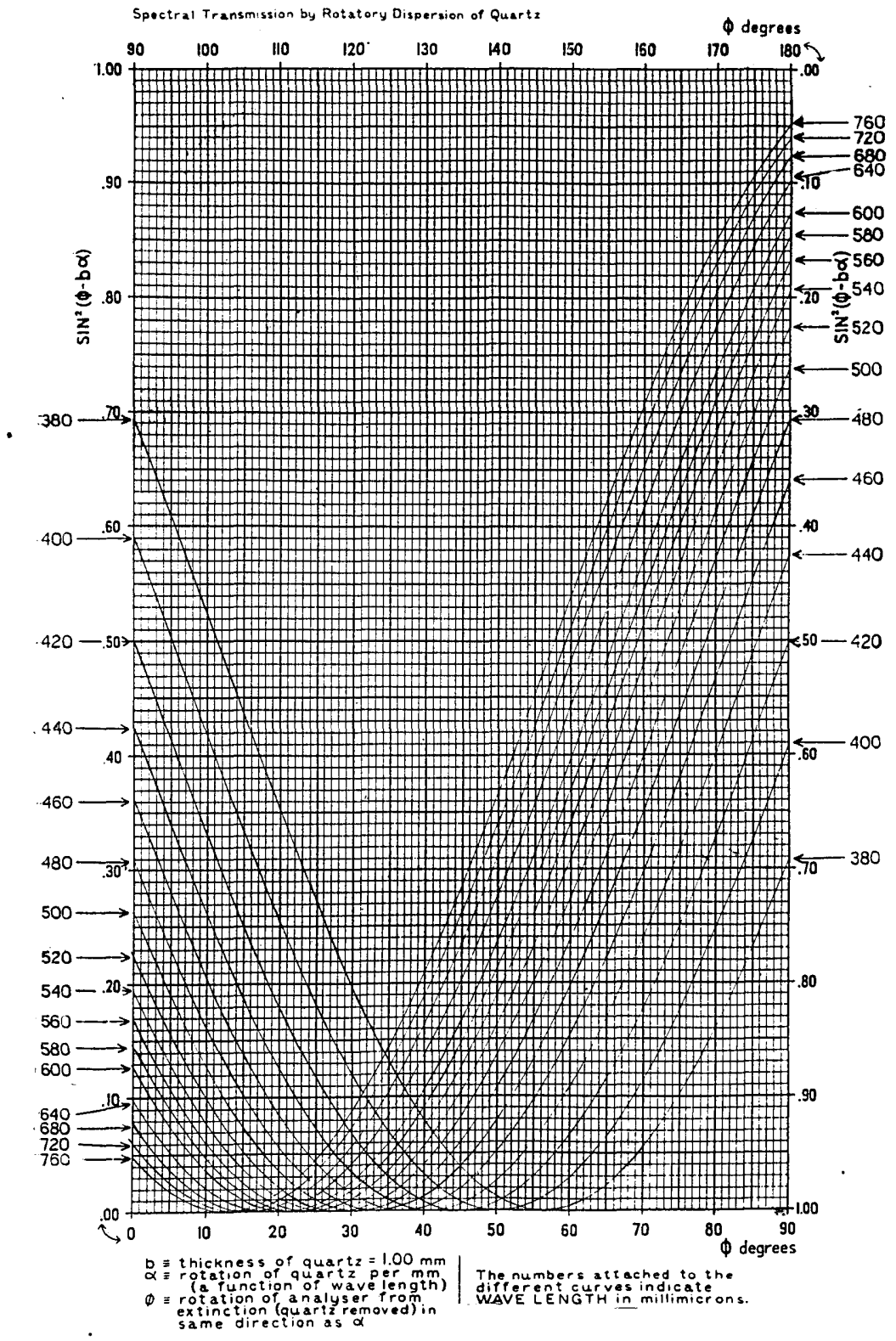


$488 \quad$ Irwin G. Priest.

Fig. 17

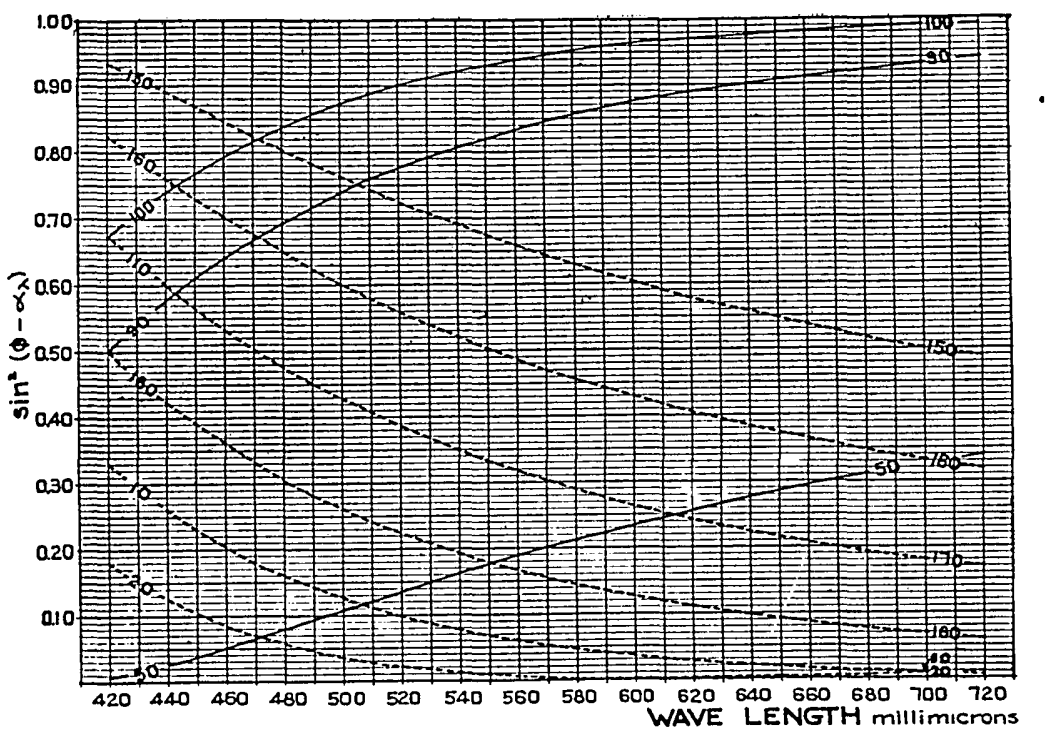

Relative Spectral Transmission of a One-millimeter Quartz plate between Nicol Prisms. Numbers attached to the curves indicate values of the angle $\phi$ in degrees. (Cf. Text, Appendix I.) 
Leucoscope and Application to Pyrometry.

FIG. 18.

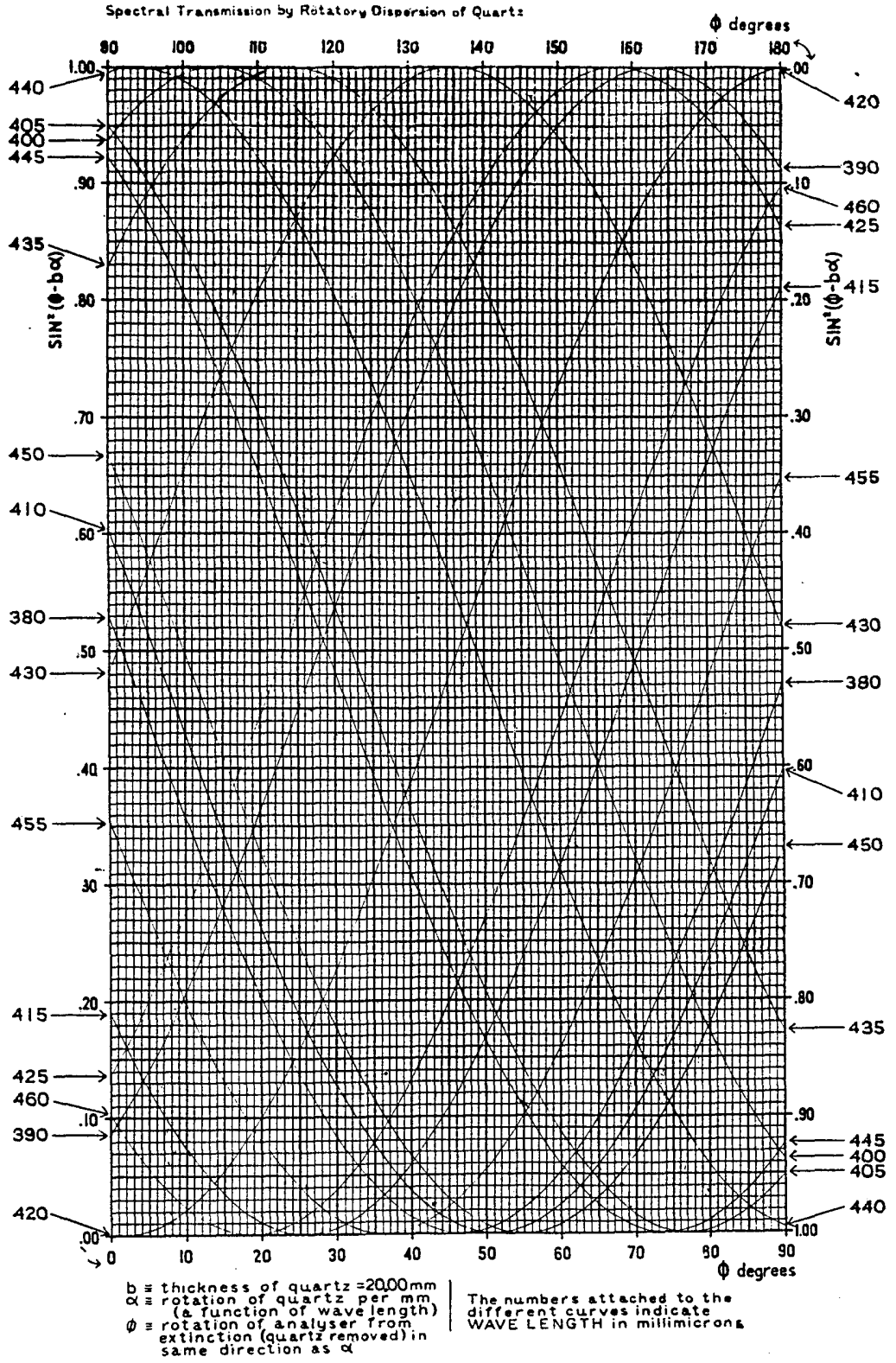


FIG. 19.

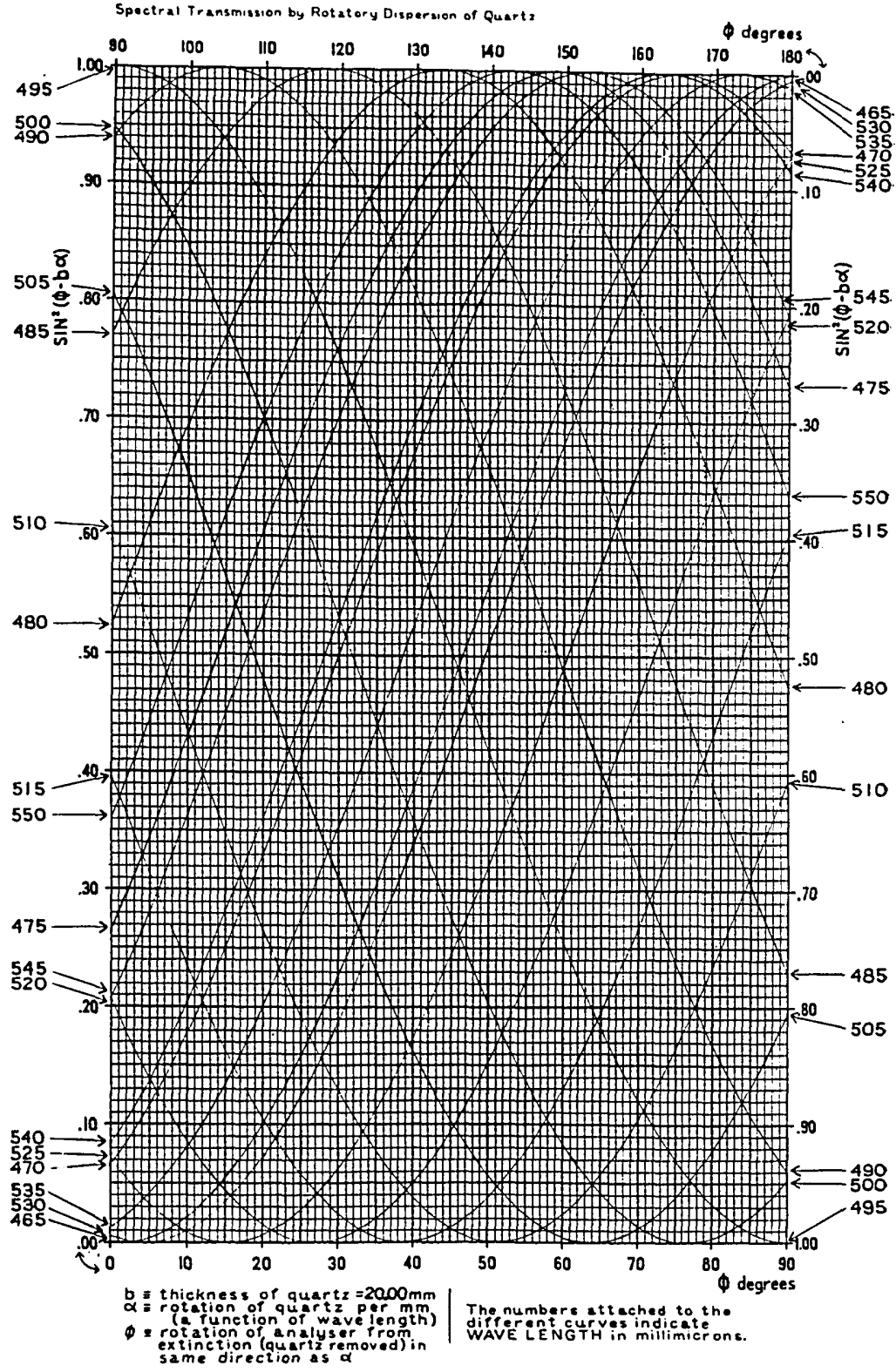


Leucoscope and Application to Pyrometry.

F1G. 20.

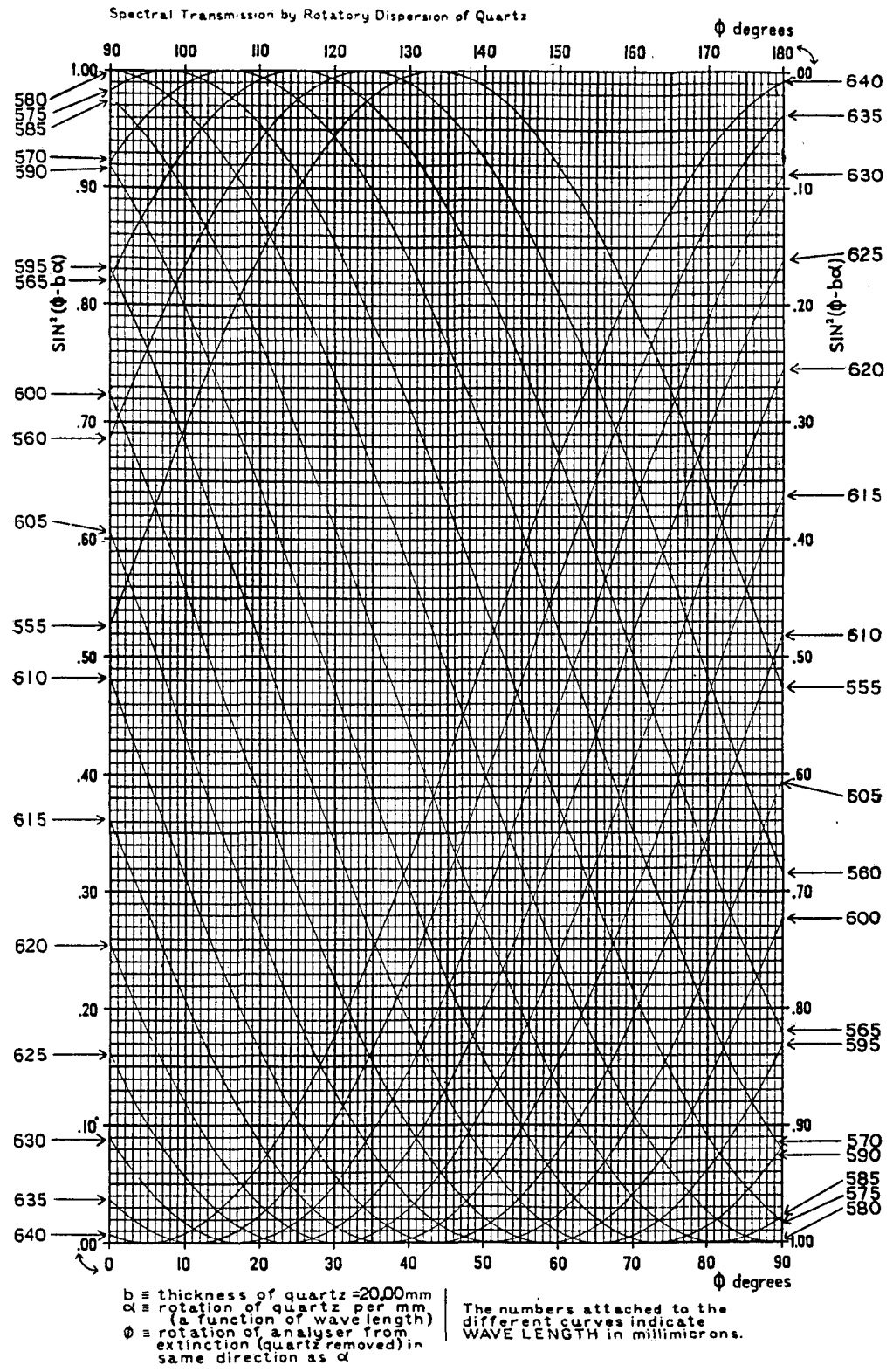


FIG. 21.

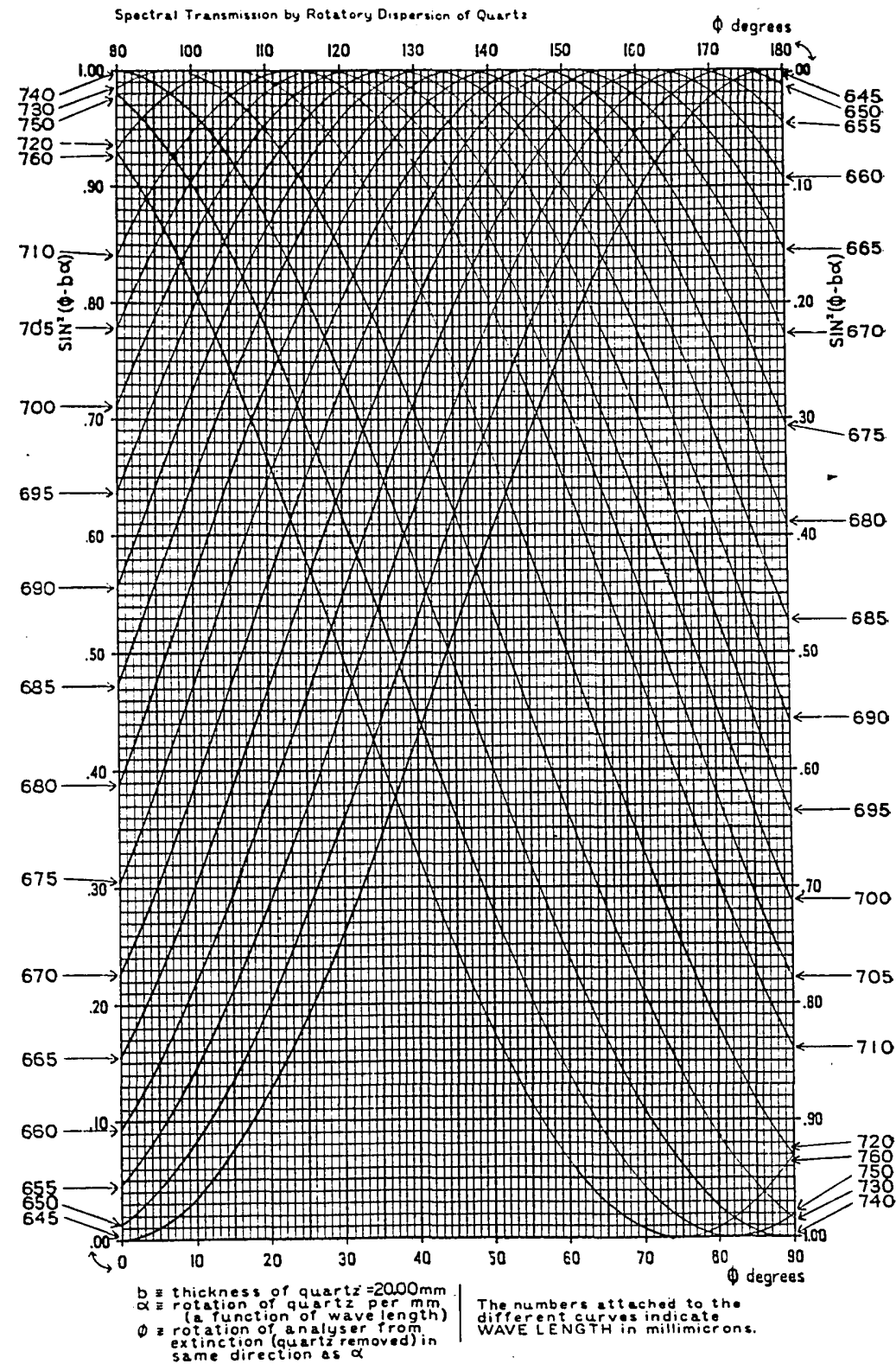


FIG. 22.

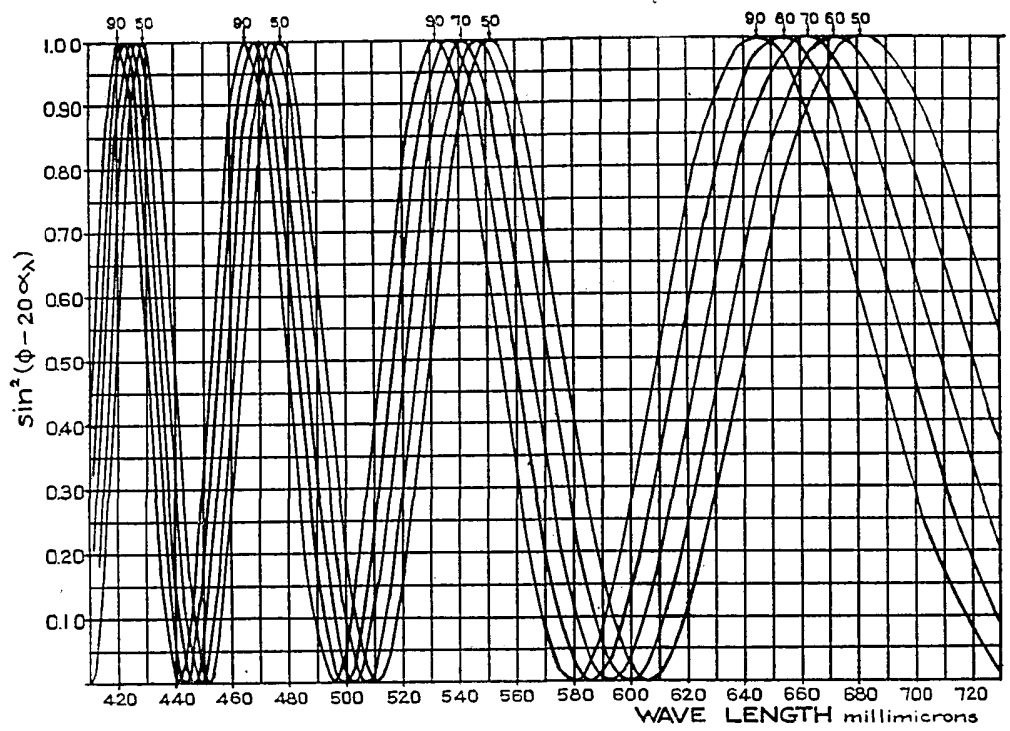

Relative Spectral Transmission of a Twenty-millimeter Quartz Plate between Nicol Prisms. Numbers attached to the curves indicate values of the angle $\phi$ in degrees. (Cf. Text, Appendix I.) These curves show the transmission for the extraordinary image in the leucoscope, $\phi$ being understood as the leucoscope reading. The transmission for the ordinary image may be obtained by reversing the ordinate scale.

\section{APPENDIX II.}

\section{Bibliography.}

(CHRONOLOGIC)

1863. Rose, Edm.: Archiv für path. Anat. und Physiol. (Virchow's Archiv) (2), 8, pp. 8r-82, and 35-46.

Description of a "Farbenmesser" which must be regarded as the prototype of the leucoscope is given as an appendix to a paper entitled "Ueber die Hallucinationen im Santonrausch." (Cf. Norris and Oliver: "System of Diseases of the Eye," Vol. 2, p. 347.)

1878. Kitao, Diro: "Zur Farbenlehre," Inang. Diss., Goettingen. Also Ann. der Phy., Beib, 4, pp. 5 ${ }^{\mathrm{I}-53}$; I880.

i882. Koenig, Arthur (and Helmholtz, in discussion): "Ueber das Leucoscope." Verh. der Phy. Gesel, Berlin, Nr. 2, pp. 23-28, Feb. 3, I882. 1882. Koenig, Arthur: "Das Leucoscope und einige mit demselben gemachte Beobachtungen." Ann. der Phy. und Chem., I7, pp. 990-1008.

1882. Koenig, Arthur: “Neue Beobachtungen mit dem Leucoscope." Verh. der Phy. Gesel, Berlin, Nr. 12, pp. 90-94. 
1883. Koenig, Arthur: "Das Leucoscope und seine Theorie." Zeit. fïr Instk., 3, pp. $20-26$.

1884. Koenig, Arthur: "Ueber einen neuen Apparat zur Diagnose der Farbenblindheit." - Centralblatt fïr prak. Augenheilk., 8, pp. 375-377. 1884. Koenig, Arthur: "Ueber ein verinfachtes Leucoscope. (OphthalmoLeucoscope.") Verh. der Phy. Gesel, Berlin, Nr. II, pp. 4r-43. (Also, Koenig's “ Abhandlungen zur Physiol. Optik," Leipzig, I903, pp. 34-36.)

1885. Kitao, Diro: "Leucoscope seine Anwendung und seine Theorie." $A b$ handlungen des Tokio Daigaku (Univerität zu Tokio), No. I2.

1888. Brodhun, Eugen : "Ueber das Leucoscope." Ann. der Phy. und Chem., 34. pp. 897-9I8.

The foregoing bibliography is believed to be complete. A thorough search of the literature indicates that there have been no further publications on this subject. No other references were found under " Farbensinn" or " Optische Inst.," in " Fortschritte der Physik," I 885 to I898, inclusive. Neither "leucoscope" nor "leucoskop" is indexed in any volume of Science Abstracts, I 898 to date, under any of the headings where it might logically appear : viz., "Vision," " Photometry," "Apparatus and Instruments," "Measurements and Use of Instruments."

Professor Nagaoka, who was acquainted with Kitao, has informed the author that neither Kitao, who died about ten years ago, nor anyone else in Japan has published anything further on the leucoscope.

The leucoscope is not indexed and apparently not mentioned in any of the following books :

“Enc. Brit.," I910-I I.

"Intern. Enc.," I9I8.

WinkelmanN: "Handbuch der Physik," Ig06.

WUELLnER: "Experimentalphysik," 5th Ed., r899.

KORSCHELT (and others): "Handwörterbuch der Naturwissenschaften," 1912.

AbNey : "Colour Measurement and Mixture," I89I.

ABNEY: "Researches in Colour Vision," I9r3.

EDRIDGE-Green : "Colour Blindness," Igog.

Koellner: "Stoerungen des Farbensinnes," rgI2.

Rosmanit : "Feststellungen der Farbentüchtigkeit," I9I4.

Luckiesh: "Color and its Applications," I9r5.

PARSONS: "Introduction to the Study of Colour Vision," I9I5. 
Although its importance in this field is evident, it is not mentioned in any of the following papers on color grading of light sources :

Ives, H. E.: "Color Measurements of Illuminants-a Résumé."

Trans. I. E. S., April, I910, p. I89.

Block: "Kennzeichnung der Farbe des Lichtes." Electrot. Zs. Heft, 46, p. I306; I9r3.

Jones: "The Color of Illuminants." Trans. I. E. S., 9, p. 687; 1914.

HYDE AND Forsythe: "The Quality of Light from an Illuminant as Indicated by its Color Temperature." Jour. Frank. Inst., I83, pp. 353-354; 19I7.

That it is practically unknown in pyrometry is indicated by the fact that it is not indexed and apparently not mentioned in either :

(I) Burgess and LeChatelier, “ High Temperature Measurements," I9I2, or

(2) "Symposium on Pyrometry," published by Am. Inst. of Min. and Metal. Eng., I920. 